NIST Technical Note 2037

\title{
Measurement Uncertainty of the Air System in the Intelligent Building Agents Laboratory
}

Dr. Amanda J. Pertzborn

This publication is available free of charge from: https://doi.org/10.6028/NIST.TN.2037

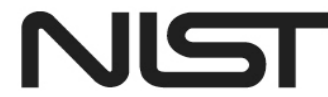

National Institute of Standards and Technology U.S. Department of Commerce 
NIST Technical Note 2037

\title{
Measurement Uncertainty in the Air System in the Intelligent Building Agents Laboratory
}

\author{
Dr. Amanda J Pertzborn \\ Energy and Environment Division \\ Engineering Laboratory
}

This publication is available free of charge from:

https://doi.org/10.6028/NIST.TN.2037

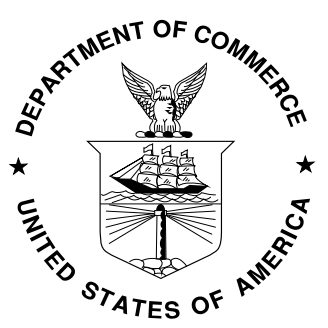

U.S. Department of Commerce Wilbur L. Ross, Jr., Secretary

National Institute of Standards and Technology Walter Copan, NIST Director and Undersecretary of Commerce for Standards and Technology 
Certain commercial entities, equipment, or materials may be identified in this document in order to describe an experimental procedure or concept adequately. Such identification is not intended to imply recommendation or endorsement by the National Institute of Standards and Technology, nor is it intended to imply that the entities, materials, or equipment are necessarily the best available for the purpose.

National Institute of Standards and Technology Technical Note 2037

Natl. Inst. Stand. Technol. Tech. Note 2037, 41 pages (March 2019) CODEN: NTNOEF

This publication is available free of charge from:

https://doi.org/10.6028/NIST.TN.2037 


\begin{abstract}
The Intelligent Building Agents Laboratory (IBAL) has been designed and constructed to demonstrate the potential for distributed, intelligent software agents to perform optimization of control systems in commercial buildings. This technical note describes the collection of experimental data to assess time-dependent variability of instrumentation in the air system. This result is combined with other uncertainty components to yield a single value of uncertainty for each instrument used to characterize the operation and performance of the air system of the IBAL.
\end{abstract}




\section{Acknowledgements}

The author recognizes Dr. James Yen of the Statistical Engineering Division at NIST for his consultation on the statistical analysis used in this report. 


\section{TABLE OF CONTENTS}

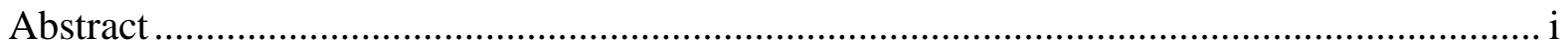

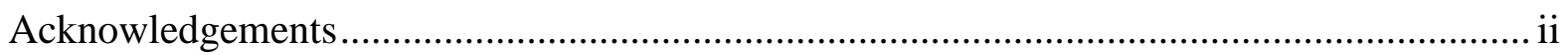

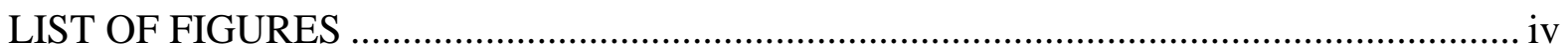

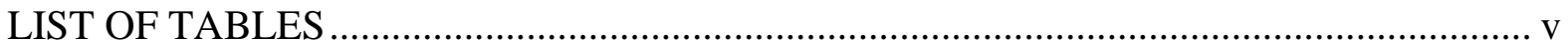

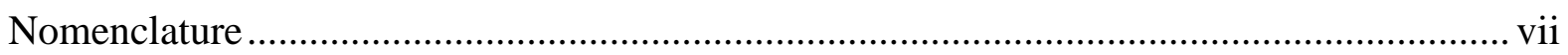

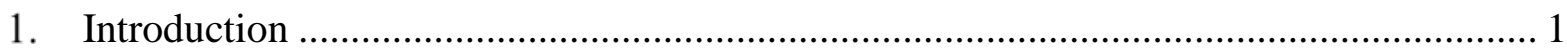

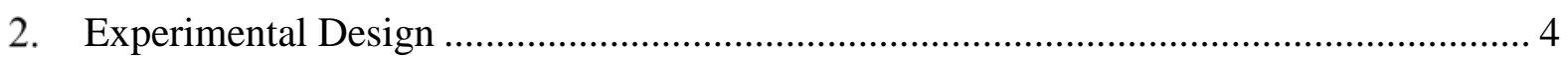

2.1. Fan Test Matrices ........................................................................................ 4

2.2. Damper and Valve Test Matrices ........................................................................ 5

2.3. Complete Test Plan ....................................................................................... 8

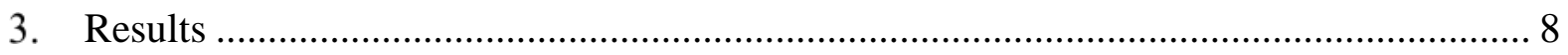

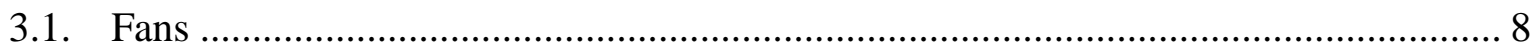

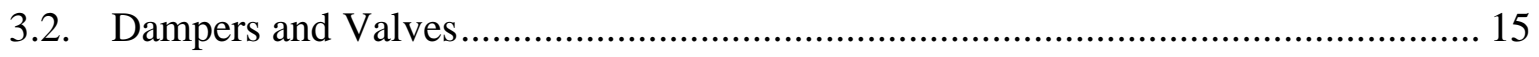

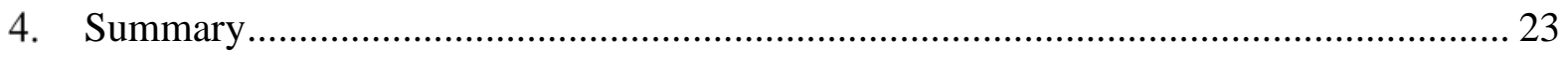

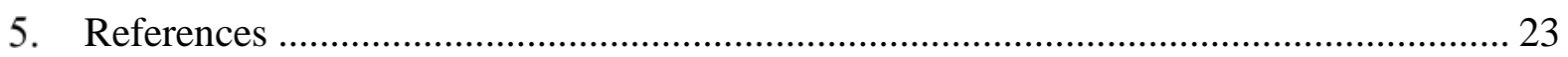

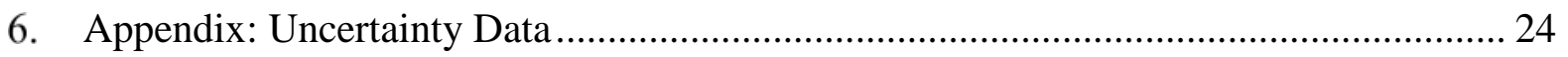




\section{LIST OF FIGURES}

Figure 1. Schematic of the IBAL air system........................................................... 2

Figure 2. Schematic of the IBAL air system showing sensor positions. .............................. 3

Figure 3. Airflow and power results for OAU fan....................................................... 8

Figure 4. Airflow, power, and pressure results for AHU1 fan. Supply + Return Airflow is the sum of the separate supply and return measurements.................................................... 9

Figure 5. Airflow, power, and pressure results for AHU2 fan. Supply + Return Airflow is the sum of the separate supply and return measurements....................................................... 10

Figure 6. Airflow and power results for EXF1 fan. .................................................. 11

Figure 7. Airflow and power results for EXF2 fan. .................................................... 11

Figure 8. Total uncertainty of measurements related to the OAU fan.............................. 12

Figure 9. Total uncertainty of measurements related to the AHU1 fan............................ 12

Figure 10. Total uncertainty of measurements related to the AHU2 fan........................... 13

Figure 11. Total uncertainty of measurements related to the EXF1 fan............................ 14

Figure 12. Total uncertainty of measurements related to the EXF2 fan........................... 14

Figure 13. Results for the OAU damper and valve actuators. ....................................... 16

Figure 14. Results for AHU1 damper actuators......................................................... 17

Figure 15. Results for AHU2 damper actuators....................................................... 17

Figure 16. Results for the VAV damper actuators........................................................ 18

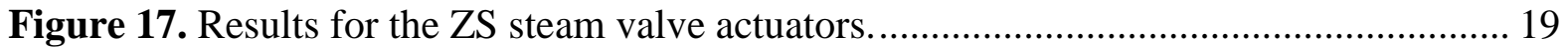

Figure 18. Total uncertainty of damper and the valve actuators in OAU........................... 20

Figure 19. Total uncertainty for damper actuators in AHU1 ......................................... 20

Figure 20. Total uncertainty for damper actuators in AHU2 ......................................... 21

Figure 21. Total uncertainty for damper actuators in the VAVs. .................................... 21

Figure 22. Total uncertainty for valve actuators in the ZSs............................................ 22 


\section{LIST OF TABLES}

Table 1. Settings of the system components ..................................................................... 4

Table 2. Test matrix for the OAU fan (fan speed $[\mathrm{Hz}]$ ) ................................................... 5

Table 3. Test matrix for the AHU (fan speed [Hz]) ......................................................... 5

Table 4. Test matrix for the EXF (fan speed [Hz]) ........................................................ 5

Table 5. Test matrix for the damper actuators in the OAU (control signal [V]).................... 6

Table 6. Test matrix for V2, the valve actuator in the OAU (control signal [V])................... 6

Table 7. Test matrix for the damper actuators in AHU1 (control signal [V])........................ 6

Table 8. Test matrix for the damper actuators in AHU2 (control signal [V])....................... 6

Table 9. Test matrix for damper actuators in the VAVs (control signal [V])....................... 7

Table 10. Test matrix for valve actuators in the ZSs (control signal [V]). .......................... 7

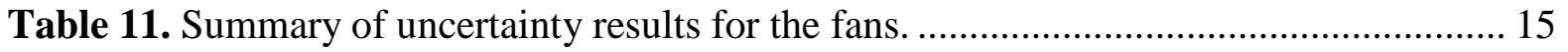

Table 12. Uncertainties for the dampers and valves. ..................................................... 23

Table 13 Uncertainty results for the instruments related to the OAU fan........................... 24

Table 14 Uncertainty results for the instruments related to the AHU1 fan......................... 24

Table 15 Uncertainty results for the instruments related to the AHU2 fan......................... 24

Table 16 Uncertainty results for the instruments related to the EXF1 fan.......................... 24

Table 17 Uncertainty results for the instruments related to the EXF2 fan.......................... 25

Table 18 Uncertainty results for the D2 actuator. .......................................................... 25

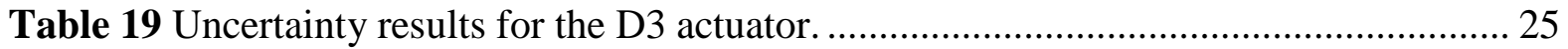

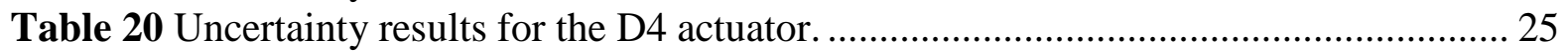

Table 21 Uncertainty results for the D5 actuator. ....................................................... 26

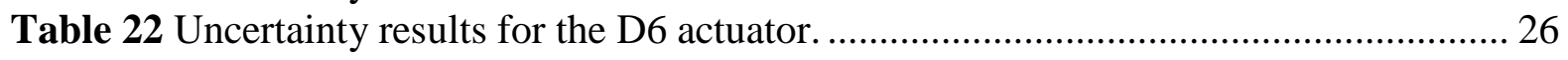

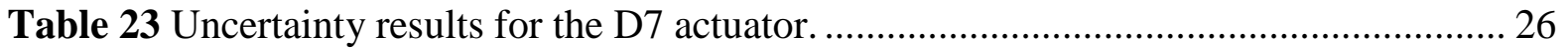

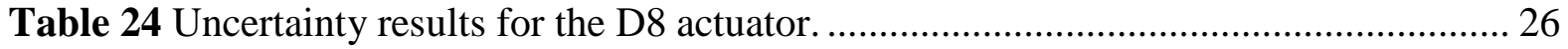

Table 25 Uncertainty results for the D15 actuator. ..................................................... 27

Table 26 Uncertainty results for the D16 actuator. ...................................................... 27

Table 27 Uncertainty results for the D17 actuator. ....................................................... 27

Table 28 Uncertainty results for the D18 actuator. ...................................................... 27

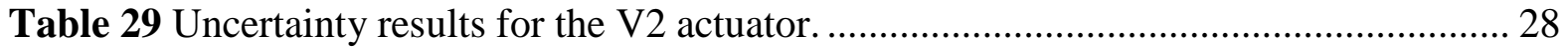

Table 30 Uncertainty results for the V14 actuator. ..................................................... 28

Table 31 Uncertainty results for the V15 actuator. ...................................................... 28

Table 32 Uncertainty results for the V16 actuator. ..................................................... 28

Table 33 Uncertainty results for the V17 actuator. ..................................................... 28

Table 34 Time-dependent variability versus instrument and manufacturer uncertainty for the

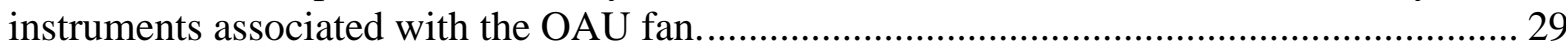

Table 34 Time-dependent variability versus instrument and manufacturer uncertainty for the instruments associated with the AHU1 fan................................................................. 29

Table 34 Time-dependent variability versus instrument and manufacturer uncertainty for the instruments associated with the AHU2 fan...

Table 34 Time-dependent variability versus instrument and manufacturer uncertainty for the instruments associated with the EXF1 fan.

Table 34 Time-dependent variability versus instrument and manufacturer uncertainty for the instruments associated with the EXF2 fan. 
Table 35 Time-dependent variability versus instrument uncertainty for the damper actuators in the OAU. 30

Table 36 Time-dependent variability versus instrument uncertainty for the damper actuators

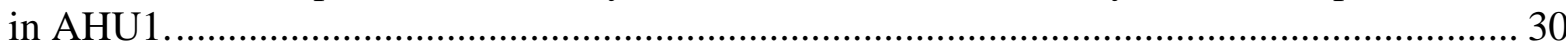
Table 37 Time-dependent variability versus instrument uncertainty for the damper actuators in AHU2. 30 Table 38 Time-dependent variability versus instrument uncertainty for the damper actuators in the VAVs. 30

Table 39 Time-dependent variability versus instrument uncertainty for the steam valve actuators. 


\section{Nomenclature}

$a$

$f$

$u$

AHU

$\mathrm{D}$

EXF

IBAL

OAU

$\mathrm{V}$

VAV

VFD

WSE

ZS calibration constant

fan speed

uncertainty

air-handling unit

damper

exhaust fan

Intelligent Building Agents

Laboratory

outdoor air unit

valve

variable air volume

variable frequency drive

water side economizer

zone simulator

\section{Subscripts}

0

1

term in the calibration curve

fit

level 1 result; term in the calibration curve 


\section{Introduction}

The Intelligent Building Agents Laboratory (IBAL) is a testbed for the evaluation and design of intelligent control algorithms. The facility emulates a small commercial building and includes both an air system and a water (hydronic) system. Within the air system, cooling loads are generated by Zone Simulators (ZSs), which emulate the zones that exist in a real building and contain electric heating elements and steam spray humidifiers. Standard commercial air-conditioning equipment, including air-handling units (AHUs) and variable-air-volume units (VAVs), supply cooling air to the ZSs. The hydronic system consists of chillers, a water side economizer (WSE), and a thermal storage tank that produce cold propylene glycol for the cooling coils in the AHUs. Each pump and fan in the system is operated using a variable-frequency drive (VFD). The hydronic side of the system was fully described in TN1933 [1], and the air side was described in TN2025 [2]. The laboratory contains nearly 300 sensors and controlled devices.

Each sensor in the IBAL has a measurement uncertainty due to contributions from sources including calibration, data acquisition, and time-dependent effects. TN1933 and TN2025 discuss calibration and data acquisition uncertainty in detail. TN1970 [3] describes the method of assessing time-dependent effects and combining all the uncertainty components into a single value for each sensor in the hydronic system. This document addresses the timedependent variability for the air system and how it is combined with the instrument uncertainty. Flow rate, pressure, and power consumption are the key values measured for the five fans, and position is the key value measured for the eleven damper and five steam valve actuators. Figure 1 shows the major components in the air system. OAU is the outdoor air unit and EXFs are the exhaust fans. The dampers are labeled with a $\mathrm{D}$ and valves are labeled with a V. The valves are used to modulate the flow rate of steam to the humidifiers. Figure 2 shows the locations of pressure and airflow measurements.

TN1970 presents the uncertainty calculation method in detail, so it will not be duplicated in this report. The final uncertainty applied to the measurements is, where relevant, a combination of: time-dependent variability, calibration uncertainty, uncertainty of the data acquisition system, and manufacturer-specified uncertainty, summed in quadrature. The calculations use a $95 \%$ confidence interval [4]. The time-dependent variability is calculated from data collected from experiments run over multiple days. The change in the instrument reading from day to day is quantified as the time-dependent variability as described in TN1970; the next section describes the experiments used to collect the necessary data. 
$\mathrm{D}=$ Damper

$\mathrm{V}=$ Valve

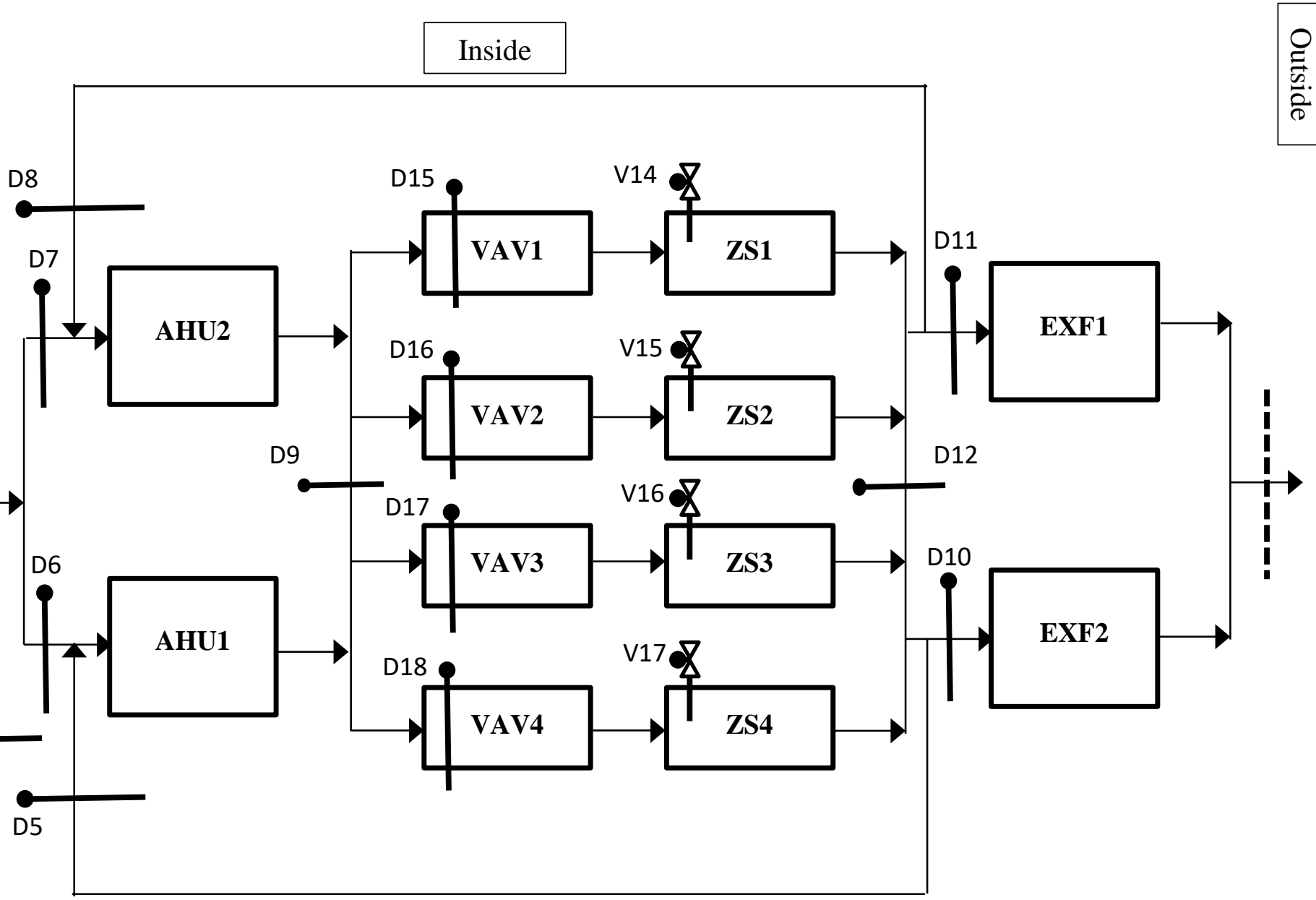

Figure 1. Schematic of the IBAL air system.

The dashed lines indicate the exterior walls of the building. 


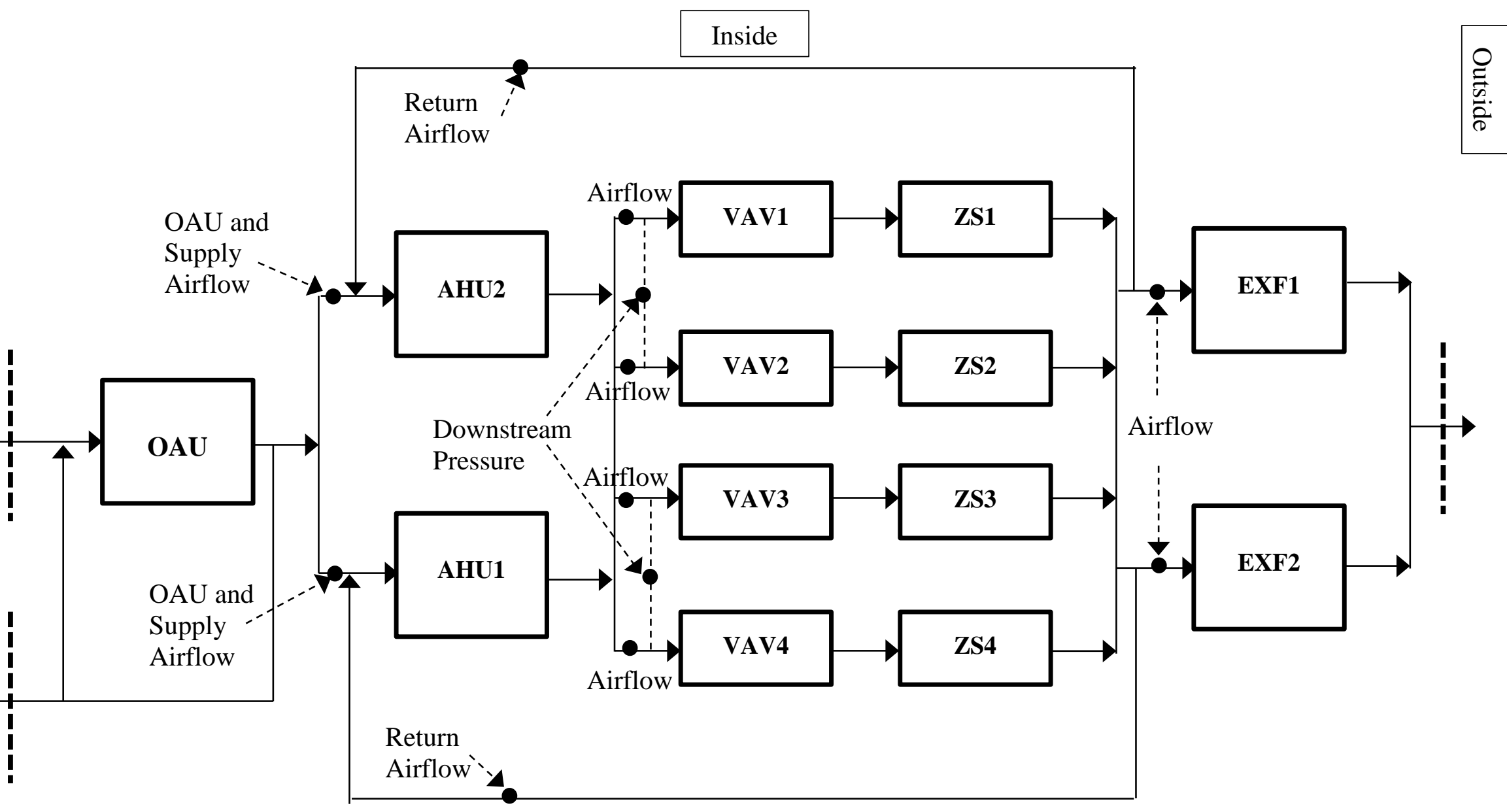

Figure 2. Schematic of the IBAL air system showing sensor positions.

The dashed lines indicate the exterior walls of the building. 


\section{Experimental Design}

This section contains a test matrix for each fan, damper, and valve in the air system. The test matrices were generated based on the anticipated system operating conditions, and the test results were used to calculate the time-dependent variability of each instrument. In all cases the fan speed is controlled by the VFD setting, which ranges from $0 \mathrm{~Hz}$ (no flow) to $60 \mathrm{~Hz}$ (maximum flow). The damper actuators in the main duct and VAVs operate based on a control voltage from (0 to 10$) \mathrm{V}$ and (2 to 10$) \mathrm{V}$, respectively, and the valve actuators operate based on a control voltage from (2 to 10) V.

\subsection{Fan Test Matrices}

There are five fans in the system: OAU, AHU1, AHU2, EXF1, and EXF2. For each fan test the only variable is the fan speed; all other fan speeds and damper positions are held constant (Table 1). All valves were closed during the fan tests except for V2 during the OAU tests. The steam line was connected to the humidifier during these tests, so when V2 was open the fan had to be on prevent steam from condensing inside the unit. Tables 2 through 4 show the fan speeds for each day of testing for each fan. The order in which the fan speeds were applied was randomly selected. Each fan was tested independently of the others. For example, on Day 1 the four runs for the OAU test were conducted first, with each run lasting 15 minutes. All other fans were set to the speed indicated in Table 1 . Then, the four runs for Day 1 of the AHU1 test were conducted, and so on.

Table 1. Settings of the system components when they are not under test.

\begin{tabular}{|c|c|}
\hline Component & Setting \\
\hline AHU1 & $60 \mathrm{~Hz}$ \\
\hline AHU2 & $60 \mathrm{~Hz}$ \\
\hline EXF1 & $30 \mathrm{~Hz}$ \\
\hline EXF2 & $30 \mathrm{~Hz}$ \\
\hline OAU & $30 \mathrm{~Hz}$ \\
\hline D2 & Closed \\
\hline D3 & Open \\
\hline D4 & Open \\
\hline D5 & $50 \%$ \\
\hline D6 & $50 \%$ \\
\hline D7 & $50 \%$ \\
\hline D8 & $50 \%$ \\
\hline D15 & Open \\
\hline D16 & Open \\
\hline D17 & Open \\
\hline D18 & Open \\
\hline
\end{tabular}


Table 2. Test matrix for the OAU fan (fan speed [Hz]).

\begin{tabular}{|c|c|c|c|c|c|}
\hline Run & Day 1 & Day 2 & Day 3 & Day 4 & Day 5 \\
\hline 1 & 30 & 45 & 15 & 60 & 15 \\
\hline 2 & 60 & 15 & 30 & 15 & 30 \\
\hline 3 & 45 & 60 & 45 & 30 & 45 \\
\hline 4 & 15 & 30 & 60 & 45 & 60 \\
\hline
\end{tabular}

Table 3. Test matrix for the AHU (fan speed [Hz]).

\begin{tabular}{|c|c|c|c|c|c|}
\hline Run & Day 1 & Day 2 & Day 3 & Day 4 & Day 5 \\
\hline 1 & 30 & 60 & 60 & 15 & 45 \\
\hline 2 & 45 & 15 & 30 & 30 & 30 \\
\hline 3 & 60 & 45 & 15 & 45 & 60 \\
\hline 4 & 15 & 30 & 45 & 60 & 15 \\
\hline
\end{tabular}

Table 4. Test matrix for the EXF (fan speed [Hz]).

\begin{tabular}{|c|c|c|c|c|c|}
\hline Run & Day 1 & Day 2 & Day 3 & Day 4 & Day 5 \\
\hline 1 & 30 & 60 & 30 & 45 & 60 \\
\hline 2 & 60 & 15 & 45 & 15 & 30 \\
\hline 3 & 15 & 45 & 15 & 30 & 15 \\
\hline 4 & 45 & 30 & 60 & 60 & 45 \\
\hline
\end{tabular}

\subsection{Damper and Valve Test Matrices}

The repeatability and reproducibility of damper and valve position is assessed by randomly actuating the device multiple times on different days. Steam was actively entering V2 during the test runs, so the OAU fan and V2 were tested at the same time. Upstream steam valves were closed for V14, V15, V16, and V17, so those valve actuators, and all damper actuators, were tested with the fans off. Tables 5 through 10 show the test matrices for the damper and valve actuators. 
Table 5. Test matrix for the damper actuators in the OAU (control signal [V]).

\begin{tabular}{|c|c|c|c|c|c|c|c|c|c|c|c|c|c|c|c|}
\hline \multirow{2}{*}{ Run } & \multicolumn{3}{|c|}{ Day 1 } & \multicolumn{3}{|c|}{ Day 2 } & \multicolumn{3}{c|}{ Day 3 } & \multicolumn{3}{|c|}{ Day 4 } & \multicolumn{3}{c|}{ Day 5 } \\
\cline { 2 - 17 } & D2 & D3 & D4 & D2 & D3 & D4 & D2 & D3 & D4 & D2 & D3 & D4 & D2 & D3 & D4 \\
\hline 1 & 0 & 5.5 & 1.5 & 1.5 & 7.5 & 1.5 & 9.5 & 9.5 & 7.5 & 9.5 & 0 & 1.5 & 0 & 9.5 & 3.5 \\
\hline 2 & 9.5 & 3.5 & 7.5 & 5.5 & 3.5 & 0 & 0 & 7.5 & 9.5 & 1.5 & 1.5 & 7.5 & 9.5 & 7.5 & 5.5 \\
\hline 3 & 1.5 & 9.5 & 5.5 & 0 & 0 & 9.5 & 1.5 & 3.5 & 0 & 0 & 5.5 & 0 & 3.5 & 5.5 & 9.5 \\
\hline 4 & 3.5 & 0 & 3.5 & 3.5 & 1.5 & 3.5 & 7.5 & 0 & 1.5 & 3.5 & 3.5 & 9.5 & 5.5 & 3.5 & 1.5 \\
\hline 5 & 7.5 & 1.5 & 0 & 9.5 & 5.5 & 5.5 & 5.5 & 5.5 & 5.5 & 7.5 & 7.5 & 3.5 & 1.5 & 1.5 & 7.5 \\
\hline 6 & 5.5 & 7.5 & 9.5 & 7.5 & 9.5 & 7.5 & 3.5 & 1.5 & 3.5 & 5.5 & 9.5 & 5.5 & 7.5 & 0 & 0 \\
\hline
\end{tabular}

Table 6. Test matrix for V2, the valve actuator in the OAU (control signal [V]).

\begin{tabular}{|c|c|c|c|c|c|}
\hline Run & Day 1 & Day 2 & Day 3 & Day 4 & Day 5 \\
\hline 1 & 4 & 6 & 2 & 2 & 8 \\
\hline 2 & 6 & 4 & 6 & 8 & 2 \\
\hline 3 & 8 & 2 & 4 & 4 & 6 \\
\hline 4 & 2 & 8 & 8 & 6 & 10 \\
\hline 5 & 10 & 10 & 10 & 10 & 4 \\
\hline
\end{tabular}

Table 7. Test matrix for the damper actuators in AHU1 (control signal [V]).

\begin{tabular}{|c|c|c|c|c|c|c|c|c|c|c|}
\hline \multirow{2}{*}{ Run } & \multicolumn{2}{|c|}{ Day 1 } & \multicolumn{2}{c|}{ Day 2 } & \multicolumn{2}{c|}{ Day 3 } & \multicolumn{2}{c|}{ Day 4 } & \multicolumn{2}{c|}{ Day 5 } \\
\cline { 2 - 11 } & D5 & D6 & D5 & D6 & D5 & D6 & D5 & D6 & D5 & D6 \\
\hline 1 & 1.5 & 5.5 & 9.5 & 0 & 0 & 3.5 & 9.5 & 1.5 & 0 & 7.5 \\
\hline 2 & 7.5 & 1.5 & 3.5 & 5.5 & 1.5 & 0 & 7.5 & 5.5 & 7.5 & 3.5 \\
\hline 3 & 3.5 & 9.5 & 1.5 & 9.5 & 5.5 & 9.5 & 0 & 3.5 & 5.5 & 0 \\
\hline 4 & 0 & 7.5 & 0 & 3.5 & 7.5 & 7.5 & 3.5 & 0 & 3.5 & 1.5 \\
\hline 5 & 5.5 & 0 & 5.5 & 1.5 & 9.5 & 5.5 & 5.5 & 7.5 & 1.5 & 5.5 \\
\hline 6 & 9.5 & 3.5 & 7.5 & 7.5 & 3.5 & 1.5 & 1.5 & 9.5 & 9.5 & 9.5 \\
\hline
\end{tabular}

Table 8. Test matrix for the damper actuators in AHU2 (control signal [V]).

\begin{tabular}{|c|c|c|c|c|c|c|c|c|c|c|}
\hline \multirow{2}{*}{ Run } & \multicolumn{2}{|c|}{ Day 1 } & \multicolumn{2}{c|}{ Day 2 } & \multicolumn{2}{c|}{ Day 3 } & \multicolumn{2}{c|}{ Day 4 } & \multicolumn{2}{c|}{ Day 5 } \\
\cline { 2 - 11 } & D7 & D8 & D7 & D8 & D7 & D8 & D7 & D8 & D7 & D8 \\
\hline 1 & 5.5 & 7.5 & 9.5 & 1.5 & 0 & 5.5 & 3.5 & 3.5 & 3.5 & 5.5 \\
\hline 2 & 0 & 5.5 & 7.5 & 5.5 & 1.5 & 9.5 & 5.5 & 0 & 0 & 0 \\
\hline 3 & 1.5 & 9.5 & 0 & 3.5 & 3.5 & 1.5 & 7.5 & 9.5 & 1.5 & 1.5 \\
\hline 4 & 7.5 & 1.5 & 5.5 & 7.5 & 5.5 & 7.5 & 9.5 & 5.5 & 9.5 & 3.5 \\
\hline 5 & 3.5 & 3.5 & 1.5 & 9.5 & 9.5 & 0 & 0 & 1.5 & 5.5 & 7.5 \\
\hline 6 & 9.5 & 0 & 3.5 & 0 & 7.5 & 3.5 & 1.5 & 7.5 & 7.5 & 9.5 \\
\hline
\end{tabular}


Table 9. Test matrix for damper actuators in the VAVs (control signal [V]).

\begin{tabular}{|c|c|c|c|c|c|c|c|c|c|c|c|c|c|c|c|c|c|c|c|c|}
\hline \multirow{2}{*}{ Run } & \multicolumn{4}{|c|}{ Day 1} & \multicolumn{4}{|c|}{ Day 2} & \multicolumn{4}{|c|}{ Day 3} & \multicolumn{4}{|c|}{ Day 4} & \multicolumn{4}{|c|}{ Day 5} \\
\hline & D15 & D16 & D17 & D18 & D15 & D16 & D17 & D18 & D15 & D16 & D17 & D18 & D15 & D16 & D17 & D18 & D15 & D16 & D17 & D18 \\
\hline 1 & 10 & 2 & 6 & 6 & 10 & 2 & 8 & 2 & 10 & 4 & 4 & 6 & 4 & 2 & 2 & 8 & 8 & 10 & 4 & 8 \\
\hline 2 & 2 & 6 & 10 & 2 & 4 & 10 & 4 & 6 & 4 & 8 & 8 & 10 & 8 & 8 & 4 & 6 & 2 & 2 & 6 & 10 \\
\hline 3 & 8 & 8 & 2 & 8 & 8 & 6 & 2 & 4 & 8 & 6 & 2 & 4 & 2 & 6 & 10 & 2 & 10 & 8 & 8 & 4 \\
\hline 4 & 6 & 4 & 8 & 4 & 6 & 8 & 6 & 10 & 6 & 10 & 6 & 2 & 6 & 10 & 8 & 10 & 6 & 6 & 2 & 6 \\
\hline 5 & 4 & 10 & 4 & 10 & 2 & 4 & 10 & 8 & 2 & 2 & 10 & 8 & 10 & 4 & 6 & 4 & 4 & 4 & 10 & 2 \\
\hline
\end{tabular}

Table 10. Test matrix for valve actuators in the ZSs (control signal [V]).

\begin{tabular}{|c|c|c|c|c|c|c|c|c|c|c|c|c|c|c|c|c|c|c|c|c|}
\hline \multirow{2}{*}{ Run } & \multicolumn{4}{|c|}{ Day 1} & \multicolumn{4}{|c|}{ Day 2} & \multicolumn{4}{|c|}{ Day 3} & \multicolumn{4}{|c|}{ Day 4} & \multicolumn{4}{|c|}{ Day 5} \\
\hline & V14 & V15 & V16 & V17 & V14 & V15 & V16 & V17 & V14 & V15 & V16 & V17 & V14 & V15 & V16 & V17 & V14 & V15 & V16 & V17 \\
\hline 1 & 4 & 10 & 4 & 8 & 8 & 6 & 8 & 6 & 8 & 2 & 10 & 6 & 10 & 2 & 10 & 6 & 2 & 2 & 4 & 2 \\
\hline 2 & 2 & 4 & 8 & 6 & 6 & 10 & 2 & 10 & 6 & 10 & 2 & 10 & 8 & 6 & 8 & 8 & 4 & 4 & 6 & 10 \\
\hline 3 & 10 & 8 & 10 & 4 & 10 & 2 & 6 & 2 & 10 & 8 & 6 & 8 & 2 & 4 & 2 & 4 & 8 & 8 & 10 & 8 \\
\hline 4 & 6 & 6 & 2 & 2 & 4 & 8 & 4 & 4 & 2 & 6 & 8 & 4 & 6 & 8 & 6 & 10 & 6 & 10 & 8 & 6 \\
\hline 5 & 8 & 2 & 6 & 10 & 2 & 4 & 10 & 8 & 4 & 4 & 4 & 2 & 4 & 10 & 4 & 2 & 10 & 6 & 2 & 4 \\
\hline
\end{tabular}




\subsection{Complete Test Plan}

For every test, data were collected on five different days. For each fan the individual run of each test lasted at least 15 minutes, and for each valve and damper actuator the individual run of each test lasted at least 7 minutes. These timeframes were selected so that the system had time to reach steady state and then acquire at least 20 data points (sample rate of $0.1 \mathrm{~Hz}$ ).

\section{Results}

This section presents the uncertainty results for the fans, dampers, and valves. The figures present the mean results and the absolute and relative uncertainties.

\subsection{Fans}

Figures 3 through 7 show the mean airflow, power, and pressure as a function of fan speed for each fan. Error bars are included on each data point, though in some cases they are too small to be seen. For the AHUs, the return airflow has an unusual shape, exhibiting a minimum somewhere near the middle of the power range. For AHU1, the airflow dips to near zero at $30 \mathrm{~Hz}$ and for AHU2 the airflow dips to its lowest point at $45 \mathrm{~Hz}$. The reason for this behavior is the combined fan curve of the AHU and the EXF associated with that AHU, as well as the system pressure. For example, when the AHU1 and EXF2 fans operate at 30 $\mathrm{Hz}$, there is no return airflow. This means that the airflow from the AHU1 fan is the same as the airflow from the EXF2 fan. Return flow results from the AHU generating more airflow than the EXF. The point at which the two fans balance (30 Hz in this case) will vary based on the position of the dampers, which will change the system pressure and the operating point on the combined fan curve.
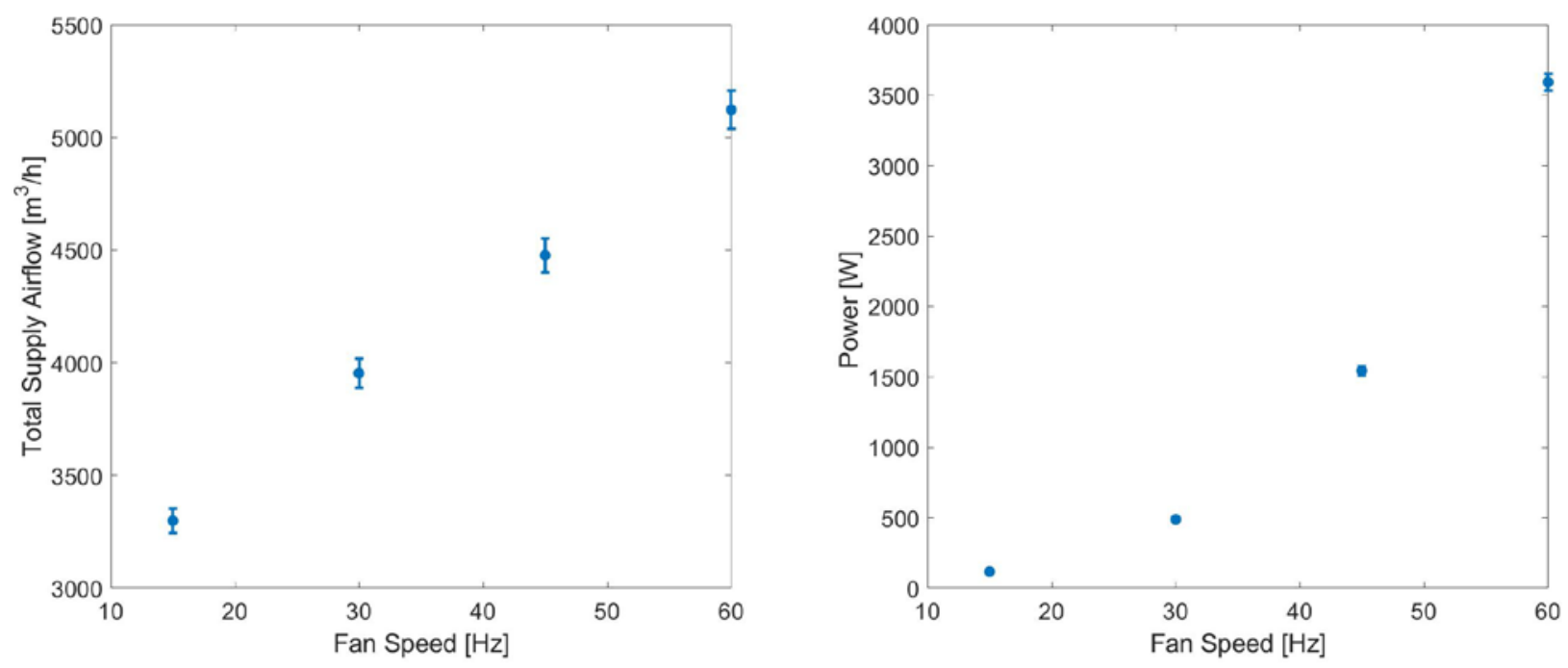

Figure 3. Airflow and power results for the OAU fan. 

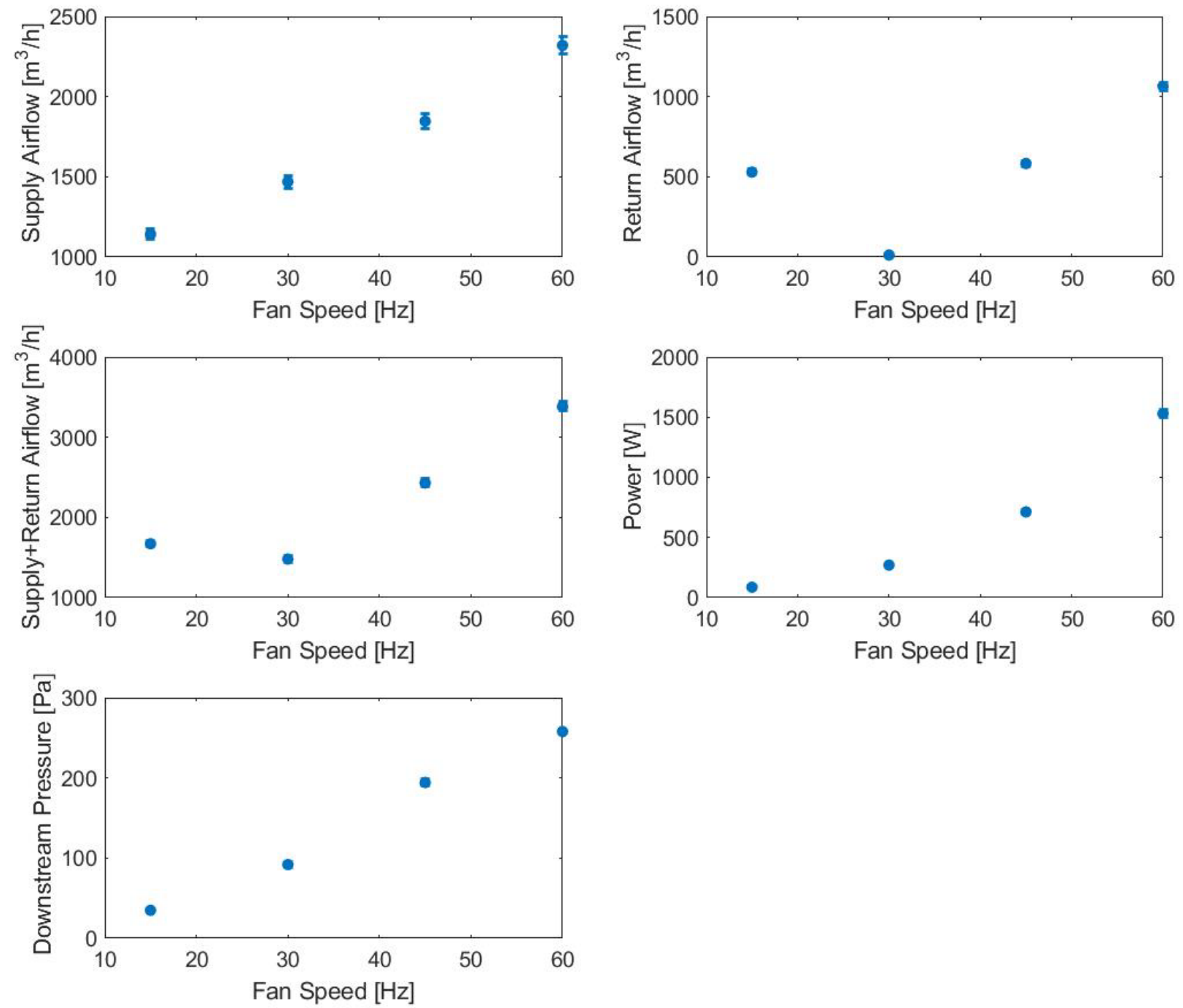

Figure 4. Airflow, power, and pressure results for the AHU1 fan. Supply + Return Airflow is the sum of the separate supply and return measurements. 

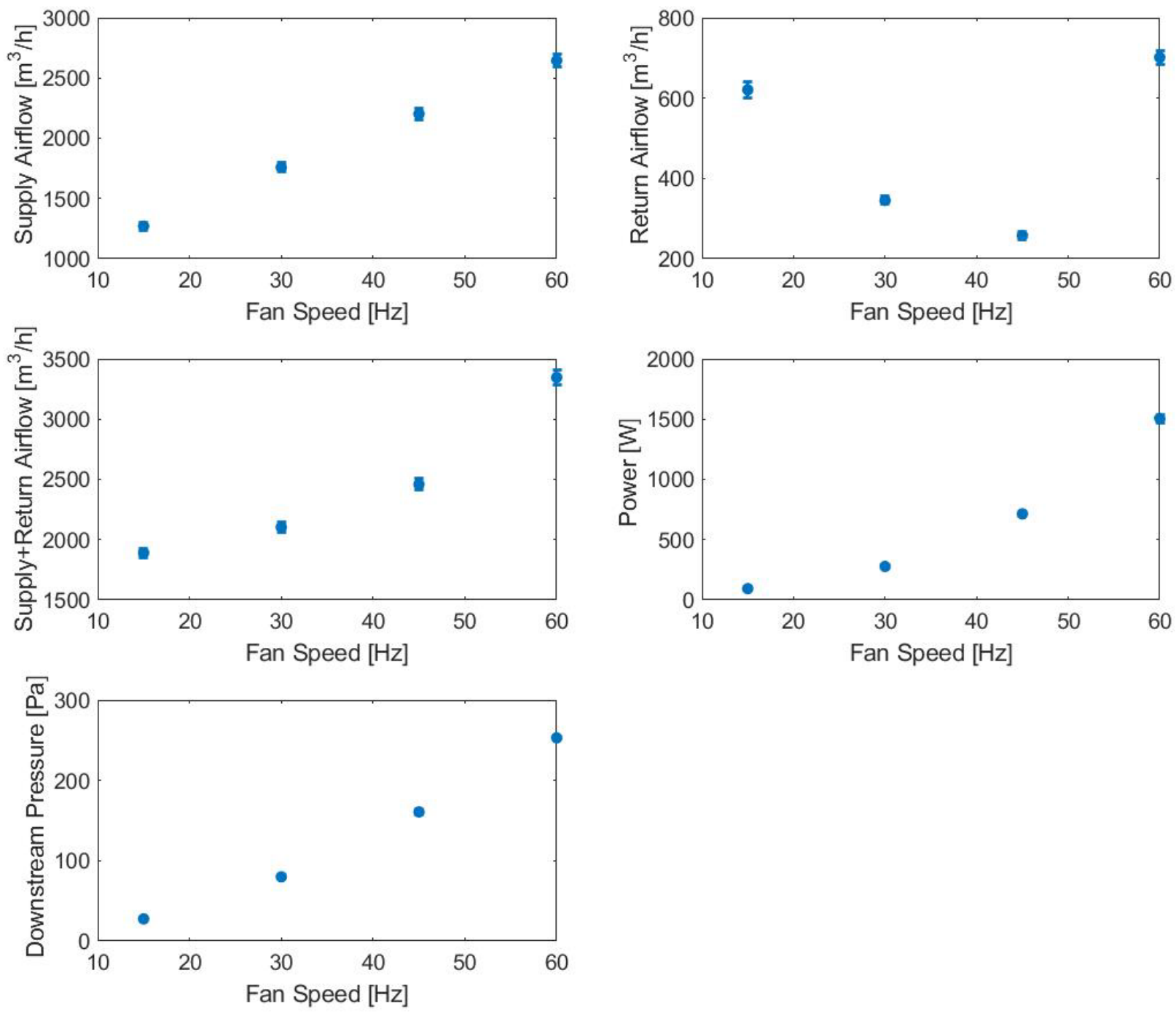

Figure 5. Airflow, power, and pressure results for the AHU2 fan. Supply + Return Airflow is the sum of the separate supply and return measurements. 

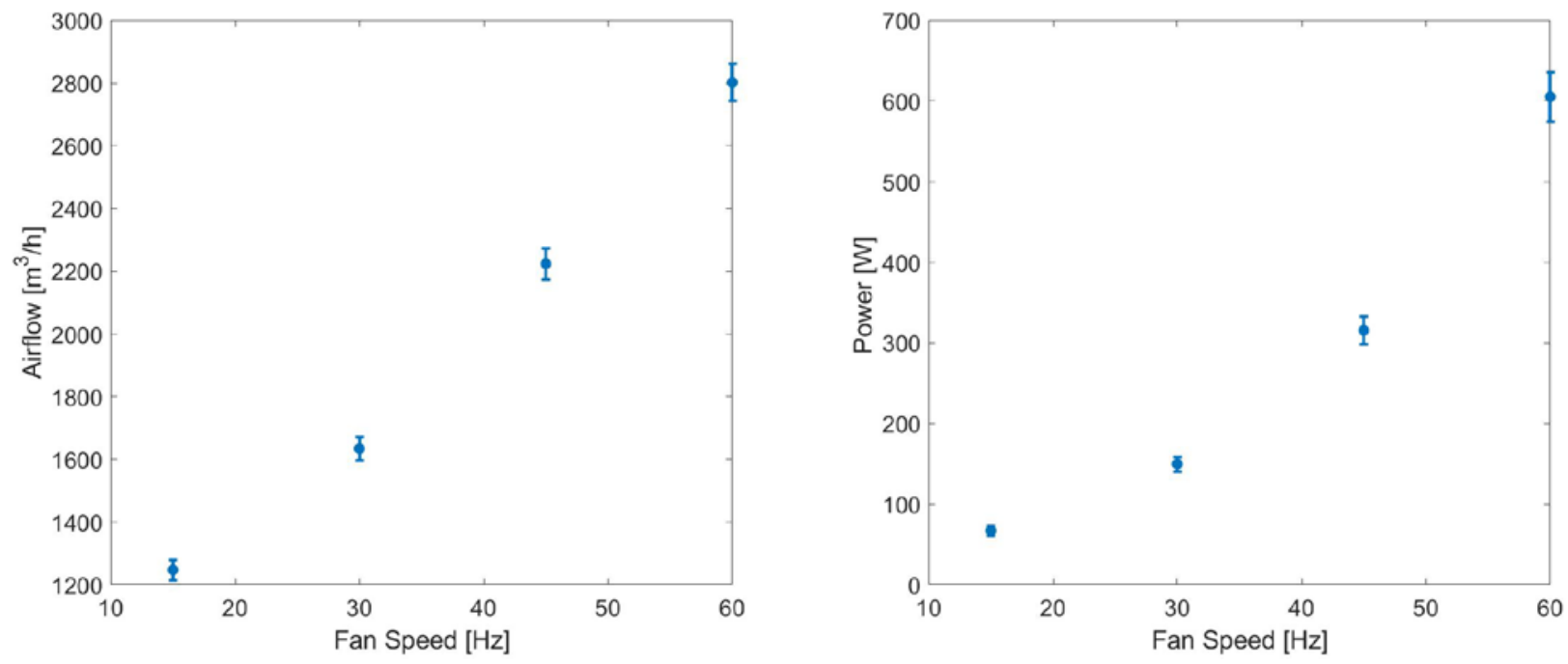

Figure 6. Airflow and power results for the EXF1 fan.
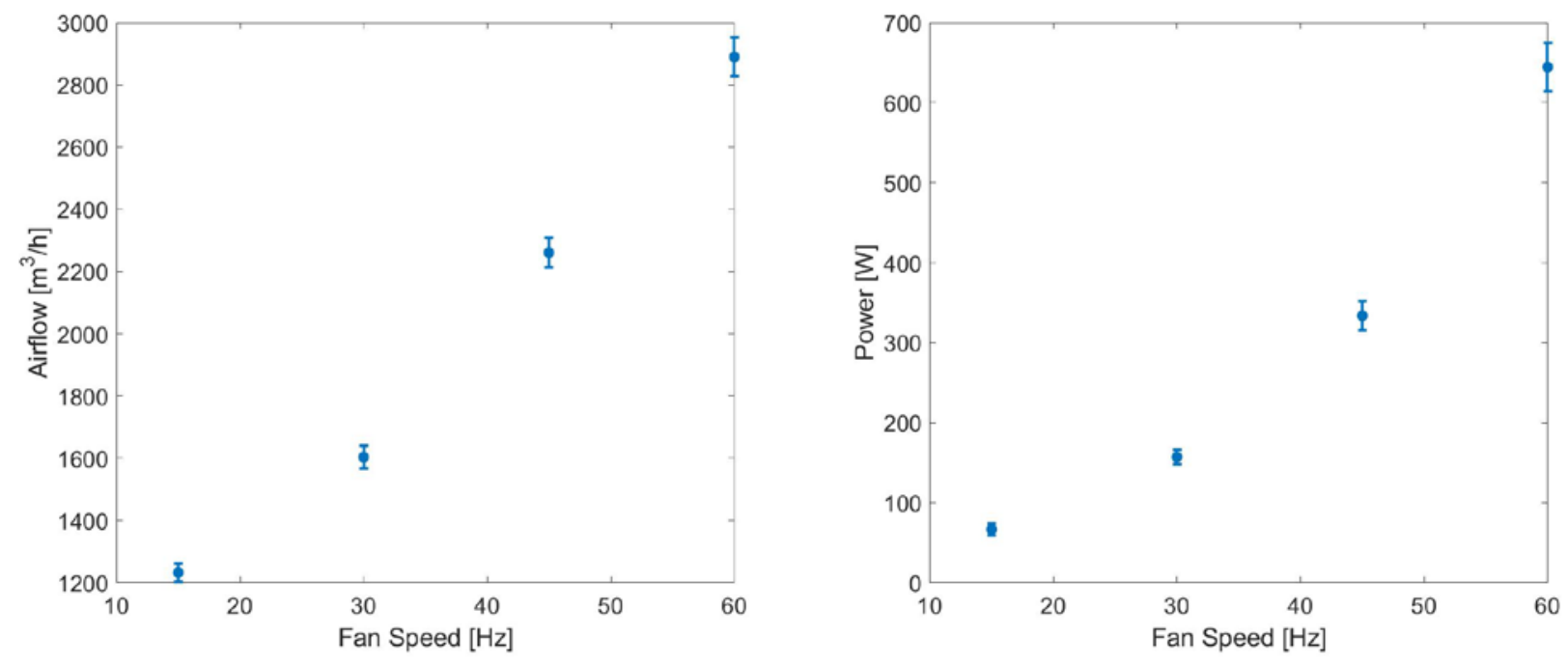

Figure 7. Airflow and power results for the EXF2 fan.

Figures 8 through 12 show the total uncertainty for the fan measurements. When the relative uncertainty is greater than $10 \%$, it is because the value of the measurement is near zero and therefore the absolute uncertainty is divided by a very small number. 

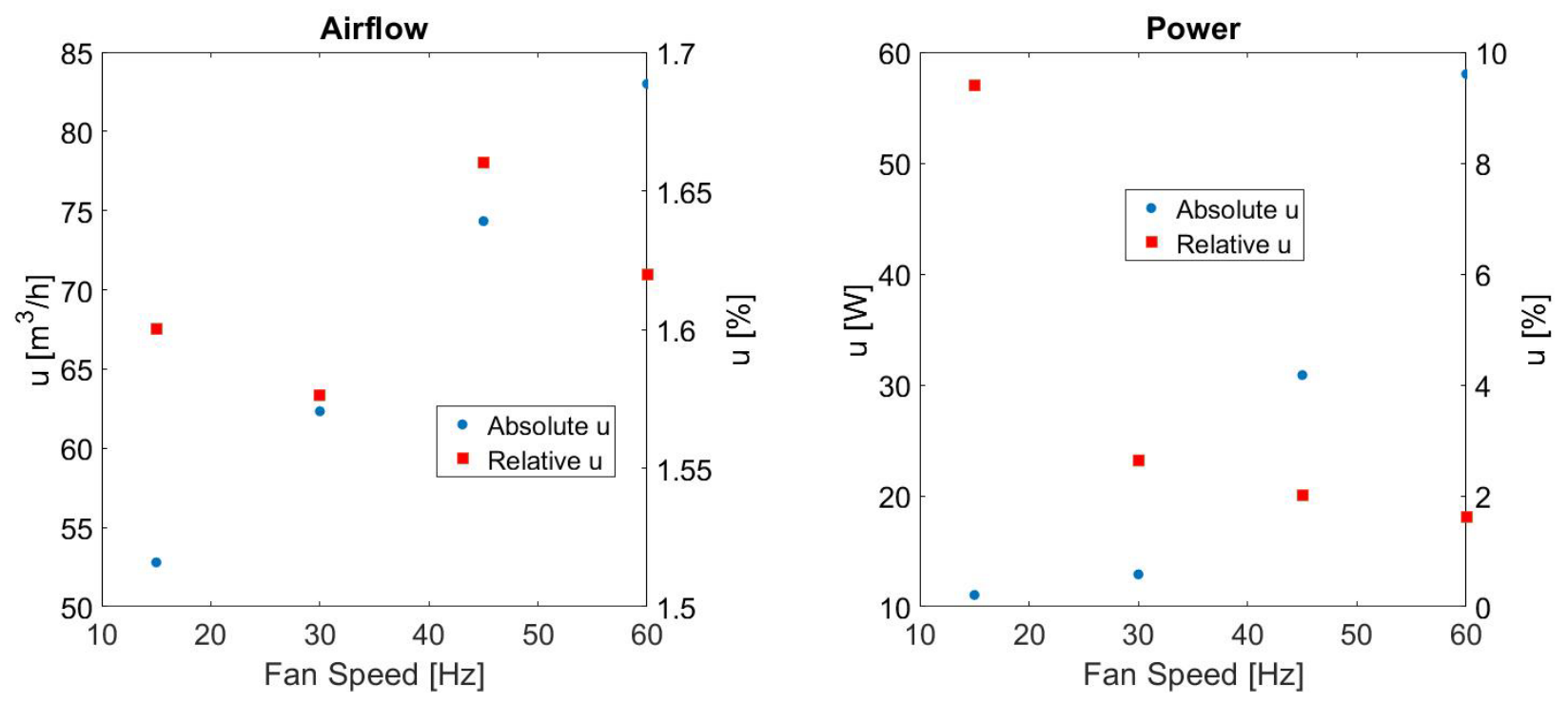

Figure 8. Total uncertainty of measurements related to the OAU fan.
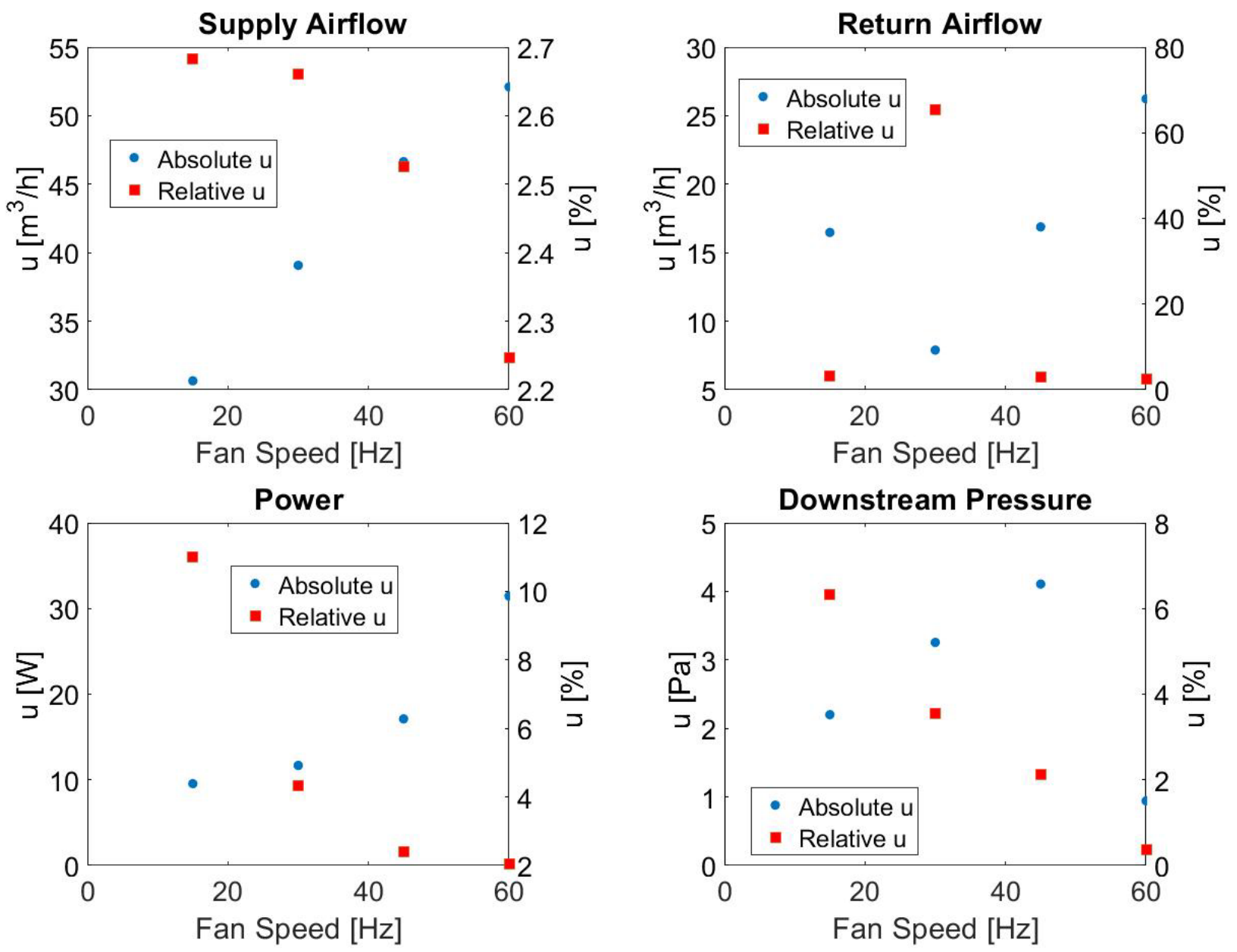

Figure 9. Total uncertainty of measurements related to the AHU1 fan. 

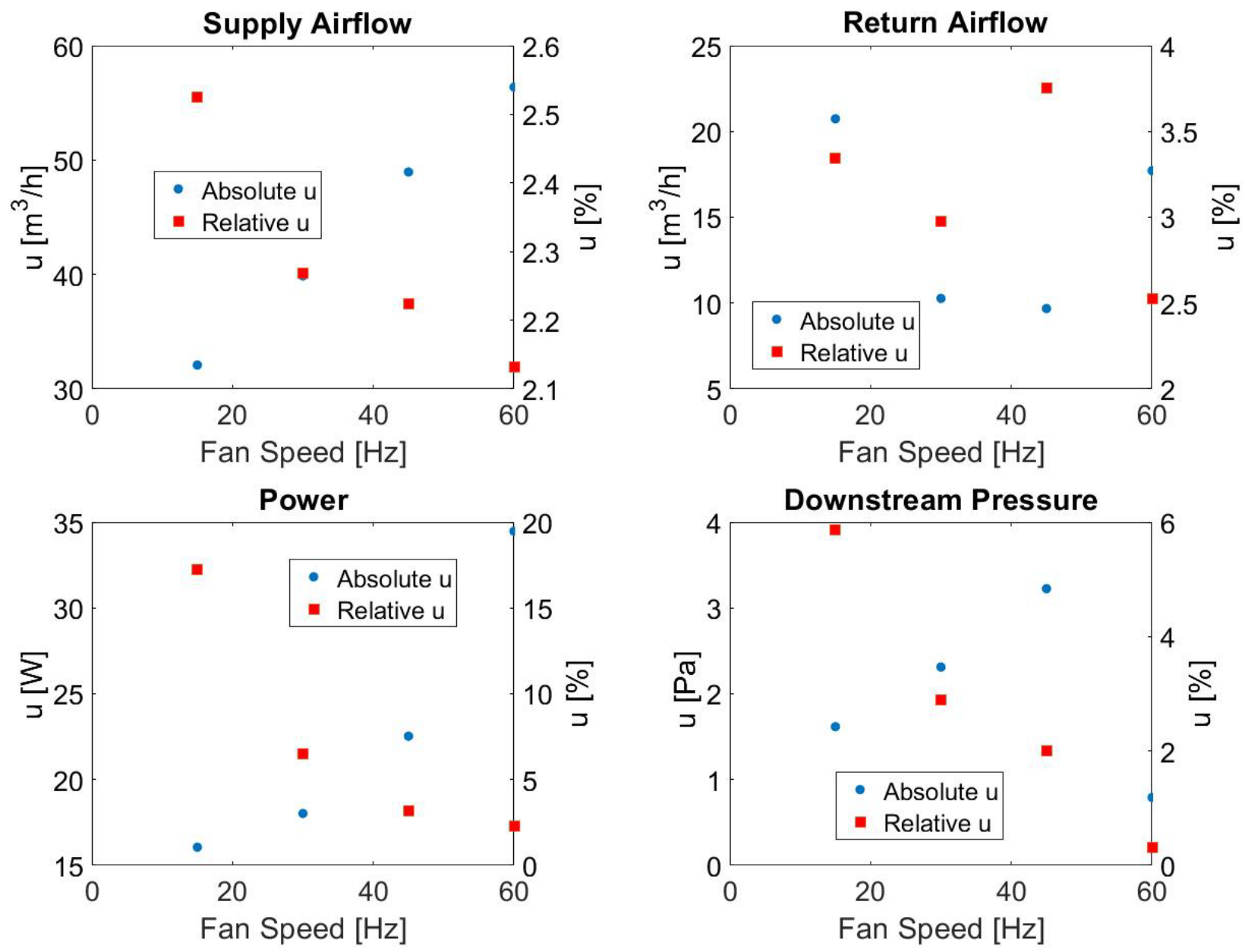

Figure 10. Total uncertainty of measurements related to the AHU2 fan. 

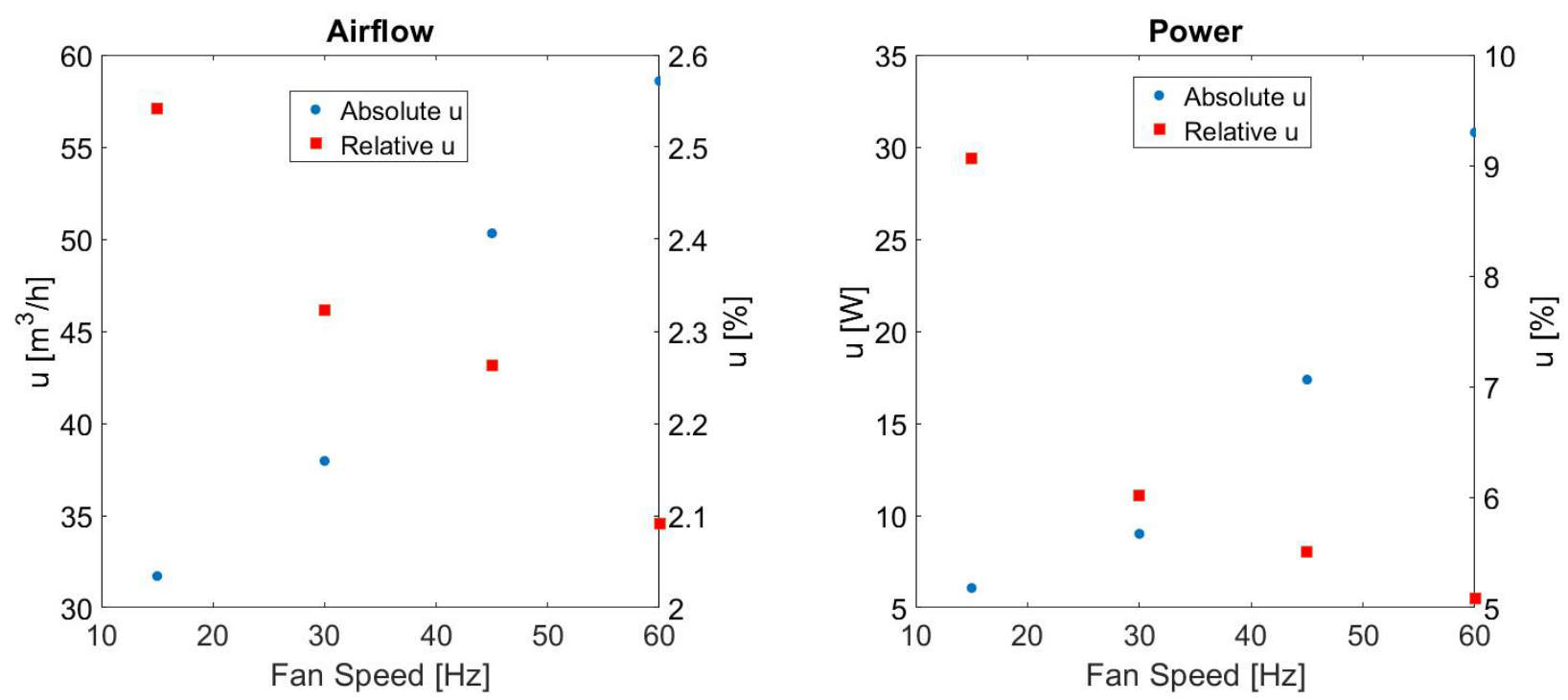

Figure 11. Total uncertainty of measurements related to the EXF1 fan.
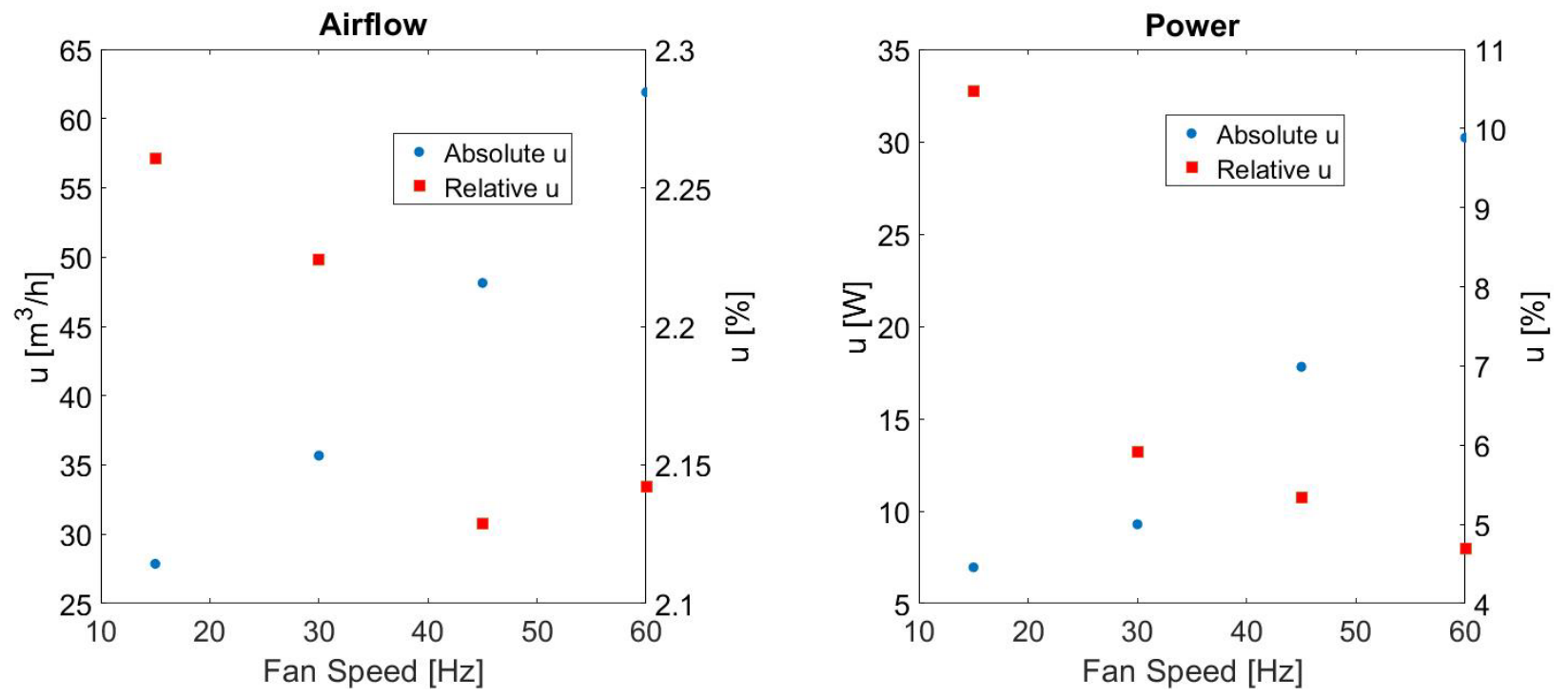

Figure 12. Total uncertainty of measurements related to the EXF2 fan.

Figure 8 through Figure 12 show that for all but the return airflow measurements (Figures 9 and 10), the uncertainty is a function of the fan speed. As such, the uncertainty for each measurement is calculated from a fit to the uncertainty curves as a function of fan speed [Hz], $f$ :

$$
\begin{gathered}
\text { Airflow, Pressure: } u=a_{0}+a_{1} f \\
\text { Power: } \frac{1}{u}=a_{0}+a_{1} f
\end{gathered}
$$


For the return airflow, which does not display a consistent trend, the uncertainty is based on the maximum of the measured uncertainties. The coefficients for each curve (see Eq. 1) and the $\mathrm{R}^{2}$ value of the curve fit are given in Table 11 . The Channel column is the data acquisition channel number assigned to the measurement and $\mathrm{S} / \mathrm{N}$ is the serial number of the instrument.

Table 11. Summary of uncertainty results for the fans.

\begin{tabular}{c|l|c|c|c|c|c} 
Fan & \multicolumn{1}{|c|}{ Measurement } & Channel & $\mathbf{S} / \mathbf{N}$ & $\mathbf{a}_{\mathbf{0}}$ & $\mathbf{a}_{\mathbf{1}}$ & $\mathbf{R}^{\mathbf{2}}$ \\
\hline \multirow{2}{*}{ OAU } & Airflow $\left[\mathrm{m}^{3} / \mathrm{h}\right]$ & $326+327$ & 707957,708382 & 42.5 & 0.684 & 0.99 \\
\cline { 2 - 7 } & Power ${ }^{-1}\left[\mathrm{~W}^{-1}\right]$ & 493 & 14090243 & 0.121 & -0.00176 & 0.92 \\
\hline \multirow{4}{*}{ AHU1 } & Supply Airflow $\left[\mathrm{m}^{3} / \mathrm{h}\right]$ & 326 & 707957 & 24.1 & 0.480 & 0.99 \\
\cline { 2 - 7 } & Return Airflow $\left[\mathrm{m}^{3} / \mathrm{h}\right]$ & 325 & 708439 & 26.2 & & \\
\cline { 2 - 7 } & Power $^{-1}\left[\mathrm{~W}^{-1}\right]$ & 59 & 14090238 & 0.132 & -0.00164 & 0.99 \\
\cline { 2 - 7 } & Pressure $[\mathrm{Pa}]$ & 5 & & 1.28 & 0.064 & 0.99 \\
\hline \multirow{5}{*}{ AHU2 } & Supply Airflow $\left[\mathrm{m}^{3} / \mathrm{h}\right]$ & 327 & 708382 & 23.8 & 0.547 & 1.00 \\
\cline { 2 - 7 } & Return Airflow $\left[\mathrm{m}^{3} / \mathrm{h}\right]$ & 334 & 708329 & 20.7 & & \\
\cline { 2 - 7 } & Power ${ }^{-1}\left[\mathrm{~W}^{-1}\right]$ & 60 & 14090246 & 0.0755 & -0.00074 & 0.96 \\
\cline { 2 - 7 } & Pressure $[\mathrm{Pa}]$ & 9 & & 0.78 & 0.054 & 0.99 \\
\hline \multirow{2}{*}{ EXF1 } & Airflow $\left[\mathrm{m}^{3} / \mathrm{h}\right]$ & 306 & 708432 & 21.4 & 0.620 & 0.98 \\
\cline { 2 - 7 } & Power ${ }^{-1}\left[\mathrm{~W}^{-1}\right]$ & 18 & 14090235 & 0.204 & -0.0030 & 0.96 \\
\hline \multirow{2}{*}{ EXF2 } & Airflow $\left[\mathrm{m}^{3} / \mathrm{h}\right]$ & 307 & 708422 & 14.7 & 0.764 & 0.98 \\
\cline { 2 - 7 } & Power ${ }^{-1}\left[\mathrm{~W}^{-1}\right]$ & 72 & 14090236 & 0.181 & -0.00255 & 0.97 \\
\hline
\end{tabular}

For the airflow measurements, the manufacturer uncertainty dominates over the timedependent variability, but for the other measurements the time-dependent variability is dominant. The Appendix contains tables with these data.

\subsection{Dampers and Valves}

For the dampers and valves, the variability of the feedback signal is assumed to be a reasonable proxy for the damper/valve position, which may be important when that signal is used by the control system to determine or set the current or future damper/valve position. Figures 14 through 17 show the feedback signal (position) versus the control signal for each device. Error bars are included in the plots, though in general they are so small that they are not visible. D2, D3, D6, and D7 do not operate across their full theoretical range of voltages. For example, when D7 (Figure 15) receives a control signal of $9.5 \mathrm{~V}$, the feedback signal is approximately $7.7 \mathrm{~V}$ instead of $9.5 \mathrm{~V}$, which is only slightly greater than the feedback when the control signal is $7.5 \mathrm{~V}$.

There are a couple of possible causes for this mismatch: 1) the two signals should match but the actuator is not working correctly; 2) there is a mismatch between the linkage on the damper and the actuator (e.g., the damper fully opens/closes before the actuator has moved through its full range). The actuator for D6 was removed and the damper was manually opened and closed to determine if the damper was operating over its full physical range. 
When the damper was fully open, the feedback signal was still well below $9.5 \mathrm{~V}$, supporting the latter explanation.
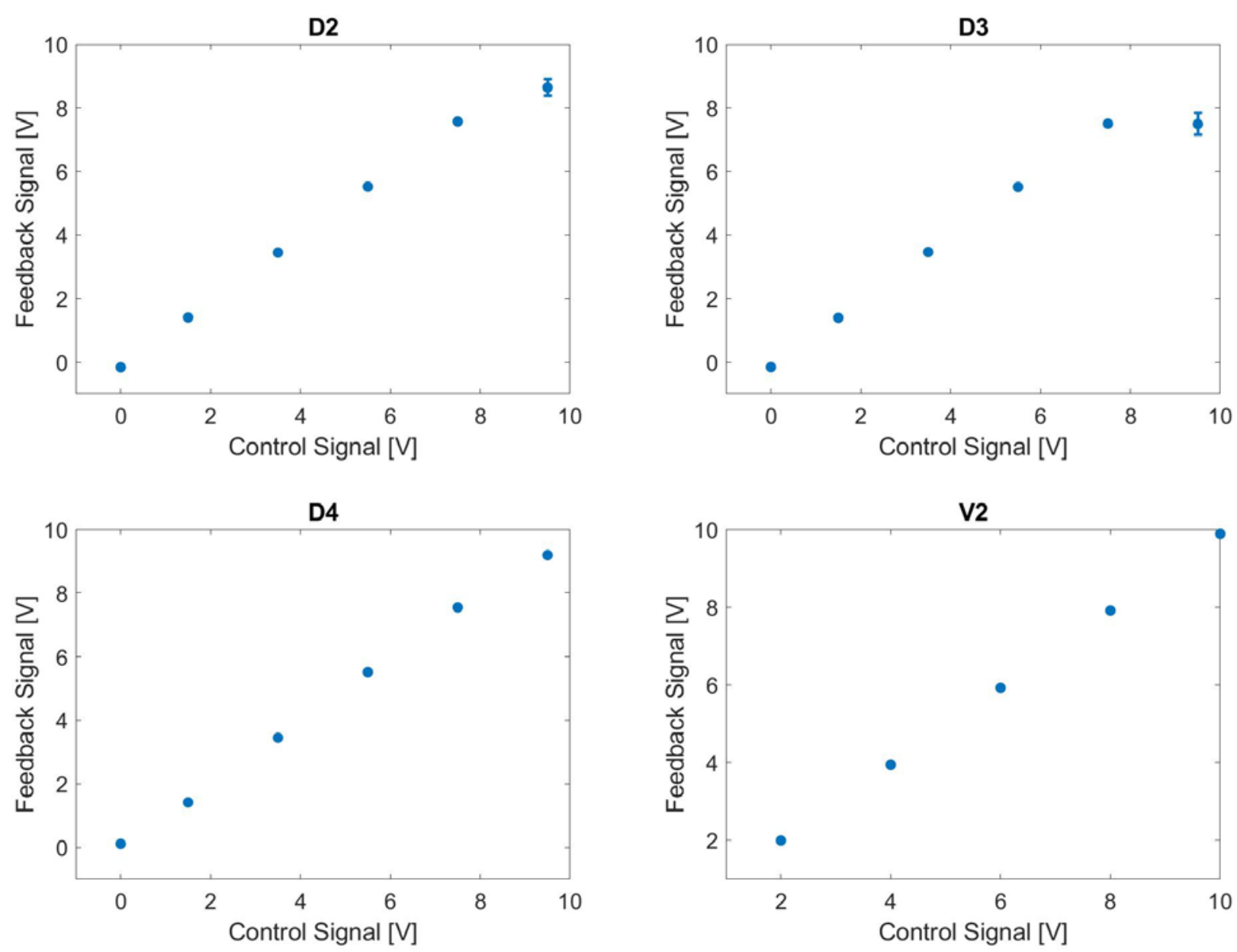

Figure 13. Results for the OAU damper and valve actuators. 

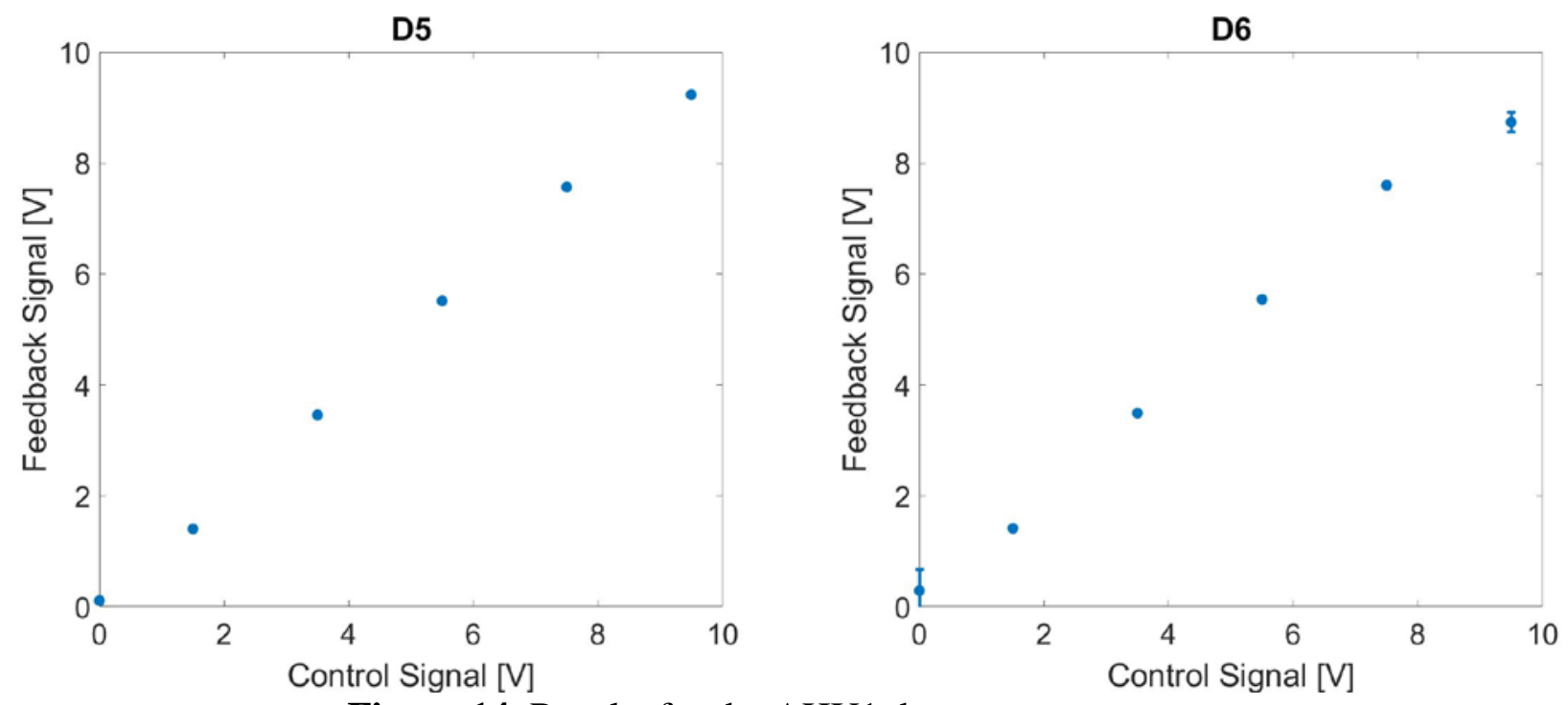

Figure 14. Results for the AHU1 damper actuators.
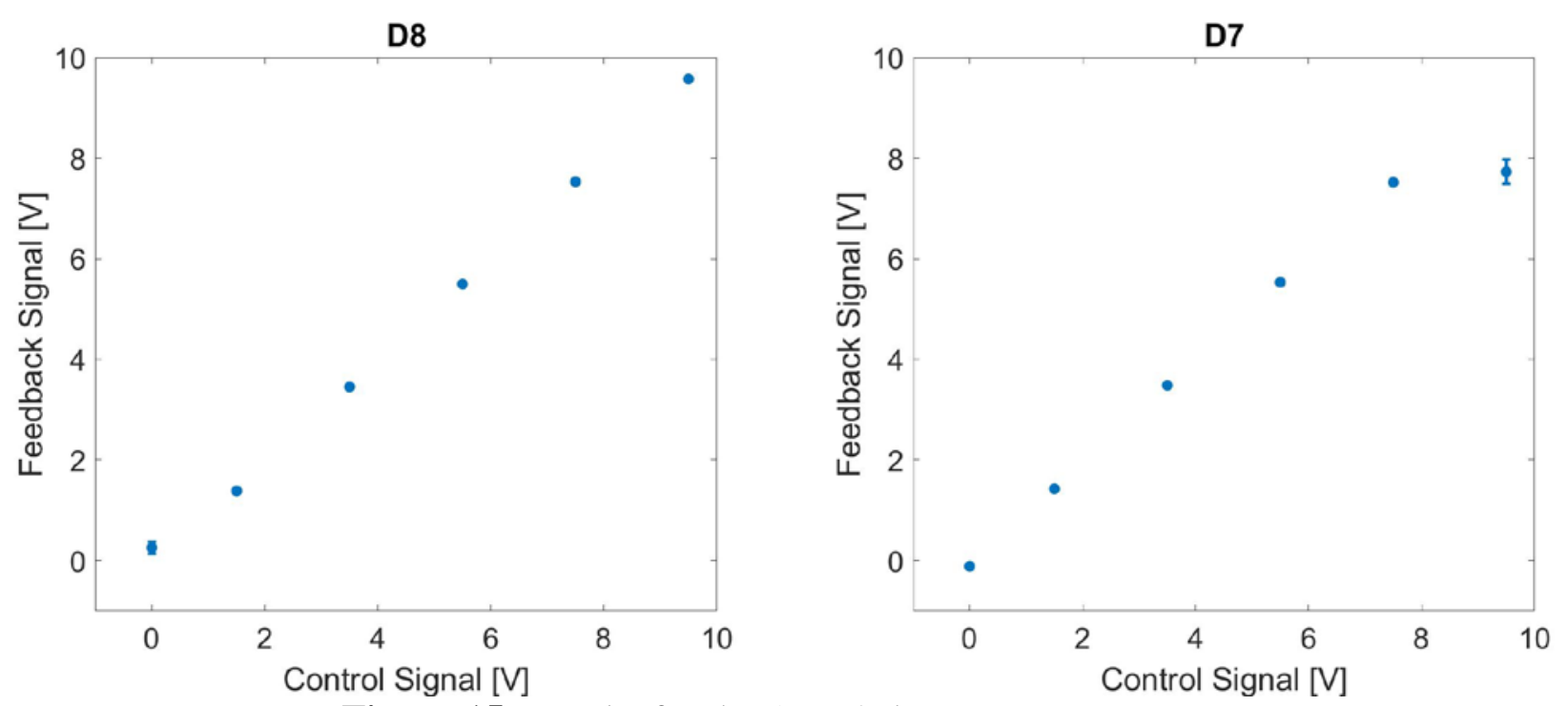

Figure 15. Results for the AHU2 damper actuators. 

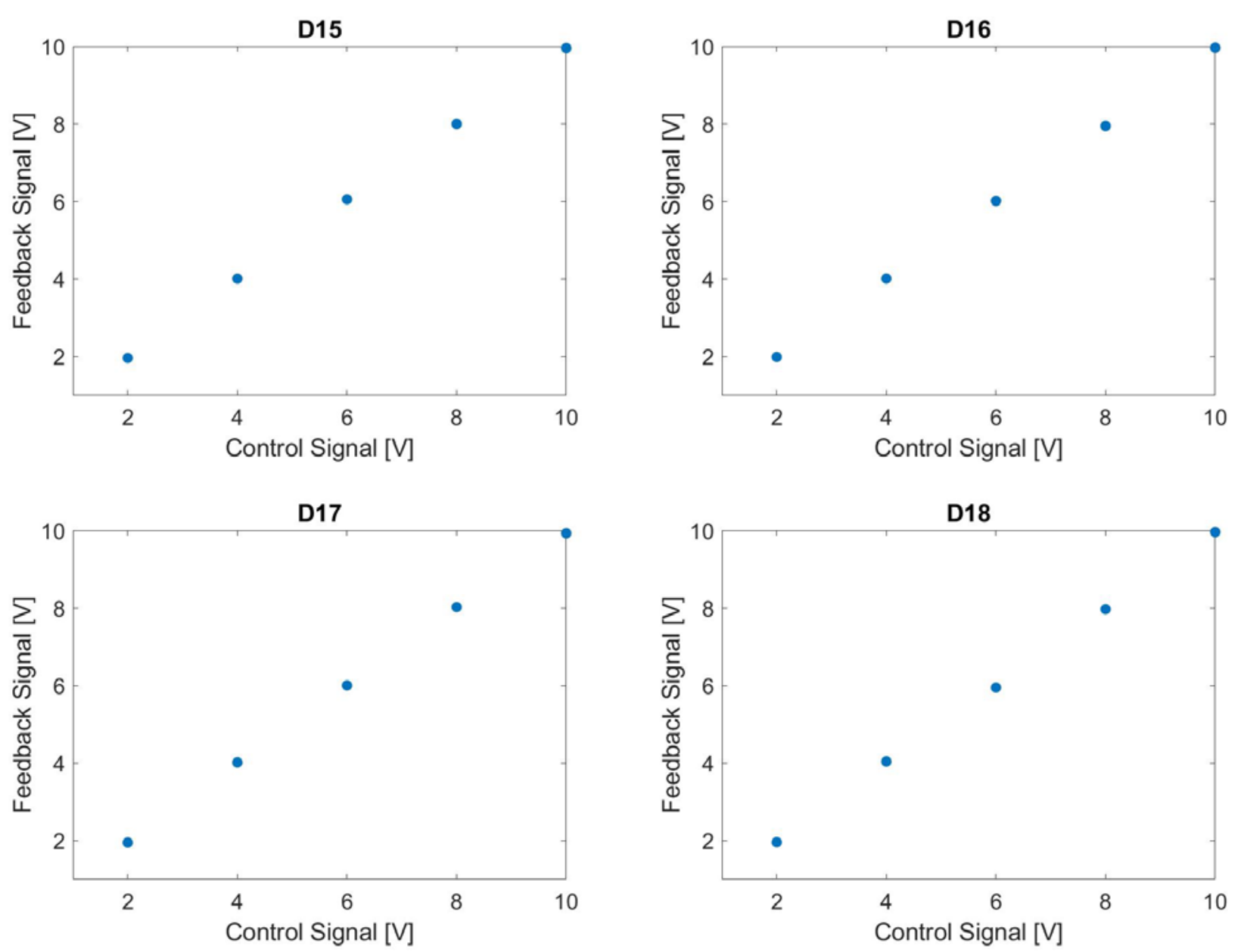

Figure 16. Results for the VAV damper actuators. 

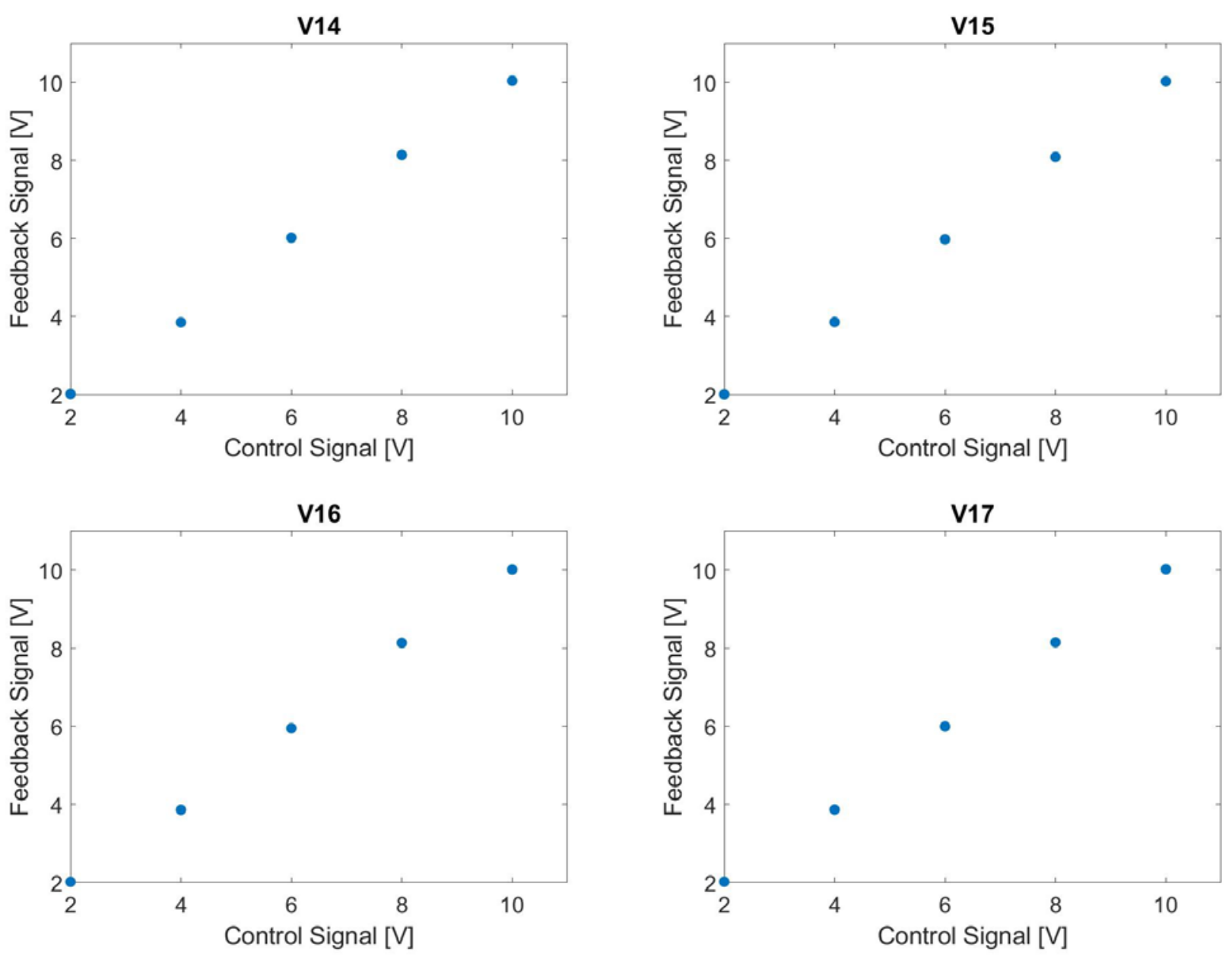

Figure 17. Results for the ZS steam valve actuators.

Figures 19 through 22 show the total uncertainty for each damper and valve actuator (see TN1970 for a full explanation of total uncertainty). In general, the uncertainty is less than $0.1 \mathrm{~V}$, but in a few cases the uncertainty is larger. The relative uncertainty is generally less than $5 \%$; where the relative uncertainty was large, it was excluded from the figure (see the Appendix for the full data set). There are two reasons for the large uncertainties. First, when the damper position is near zero the uncertainty is divided by a small number, which can cause the relative uncertainty to be large. Second, some dampers display a large range of feedback values at the fully open position. D2, D3, D6, and D7 were mentioned earlier because the damper does not operate across the actuator's full range, and, as shown in Table 12, those dampers have greater uncertainty at the upper range of control signals. In addition, D6 and D8 have greater uncertainty at the low end of their range. The timedependent variability dominates the uncertainty calculation (see the Appendix for data tables). 


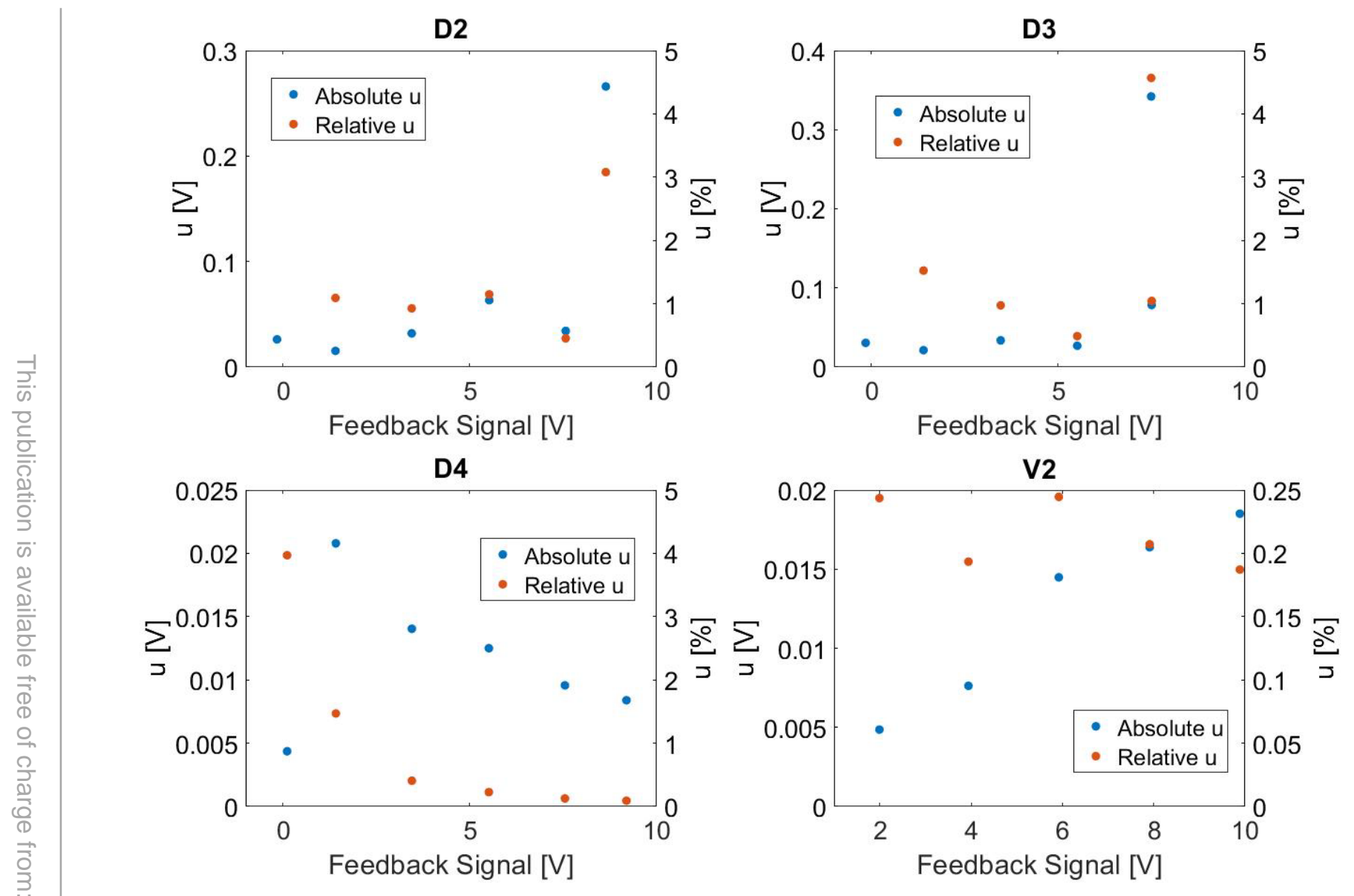

Figure 18. Total uncertainty of the damper and valve actuators in OAU.
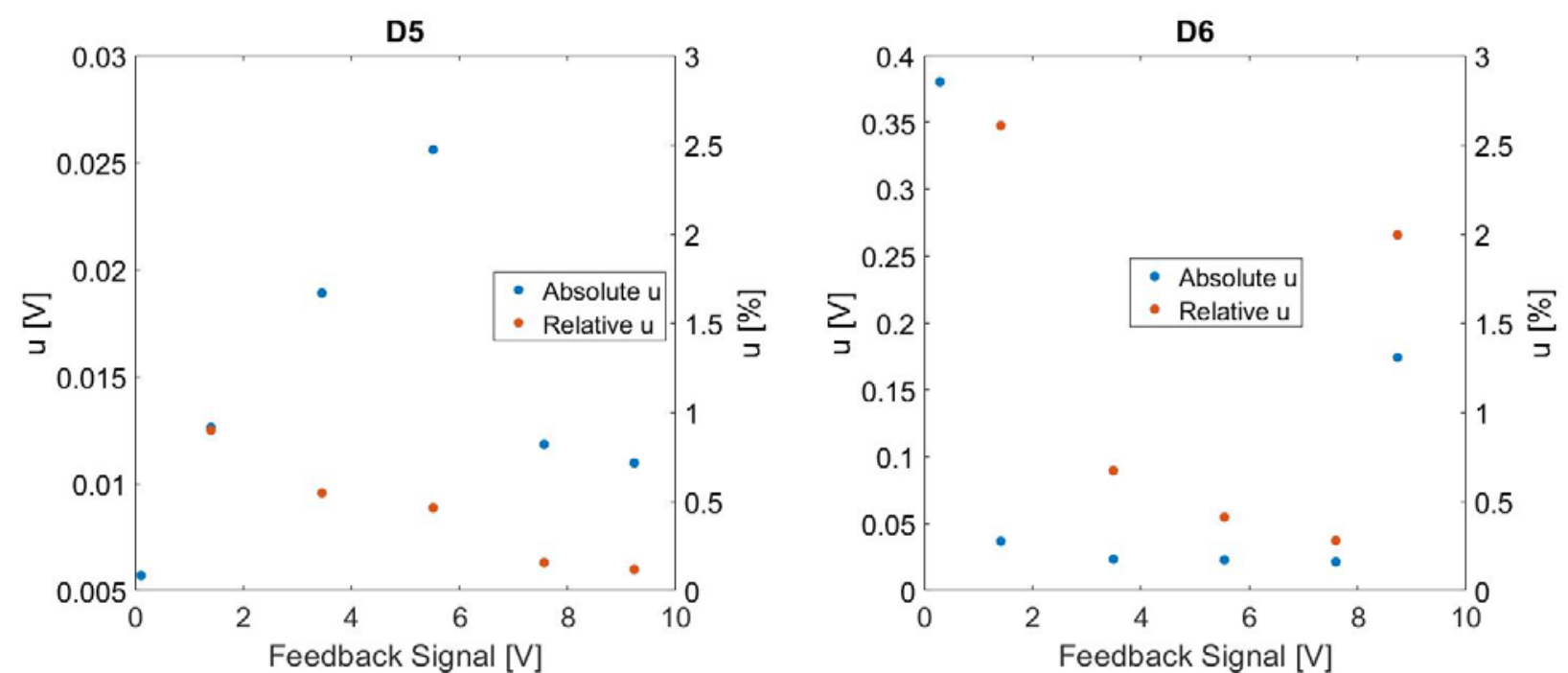

Figure 19. Total uncertainty for the damper actuators in AHU1. 

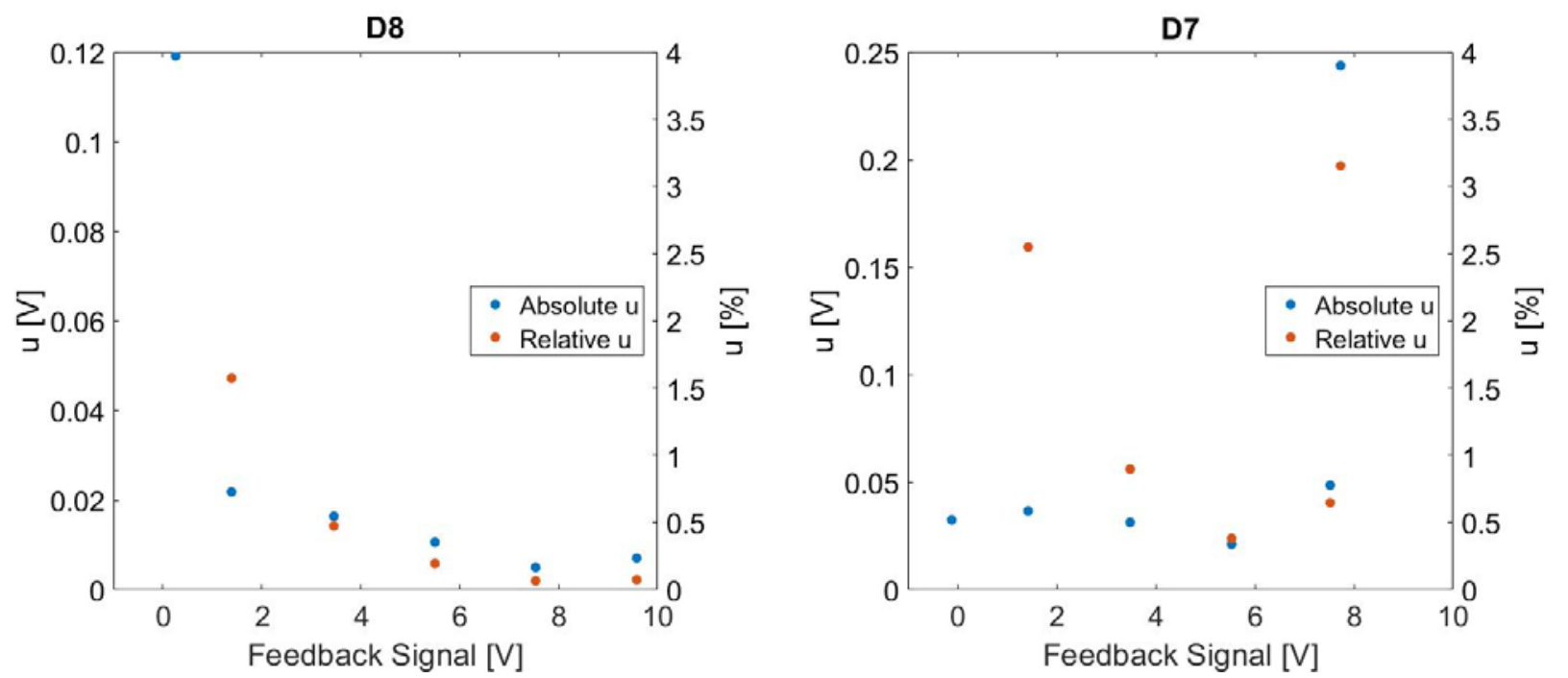

Figure 20. Total uncertainty for the damper actuators in AHU2.
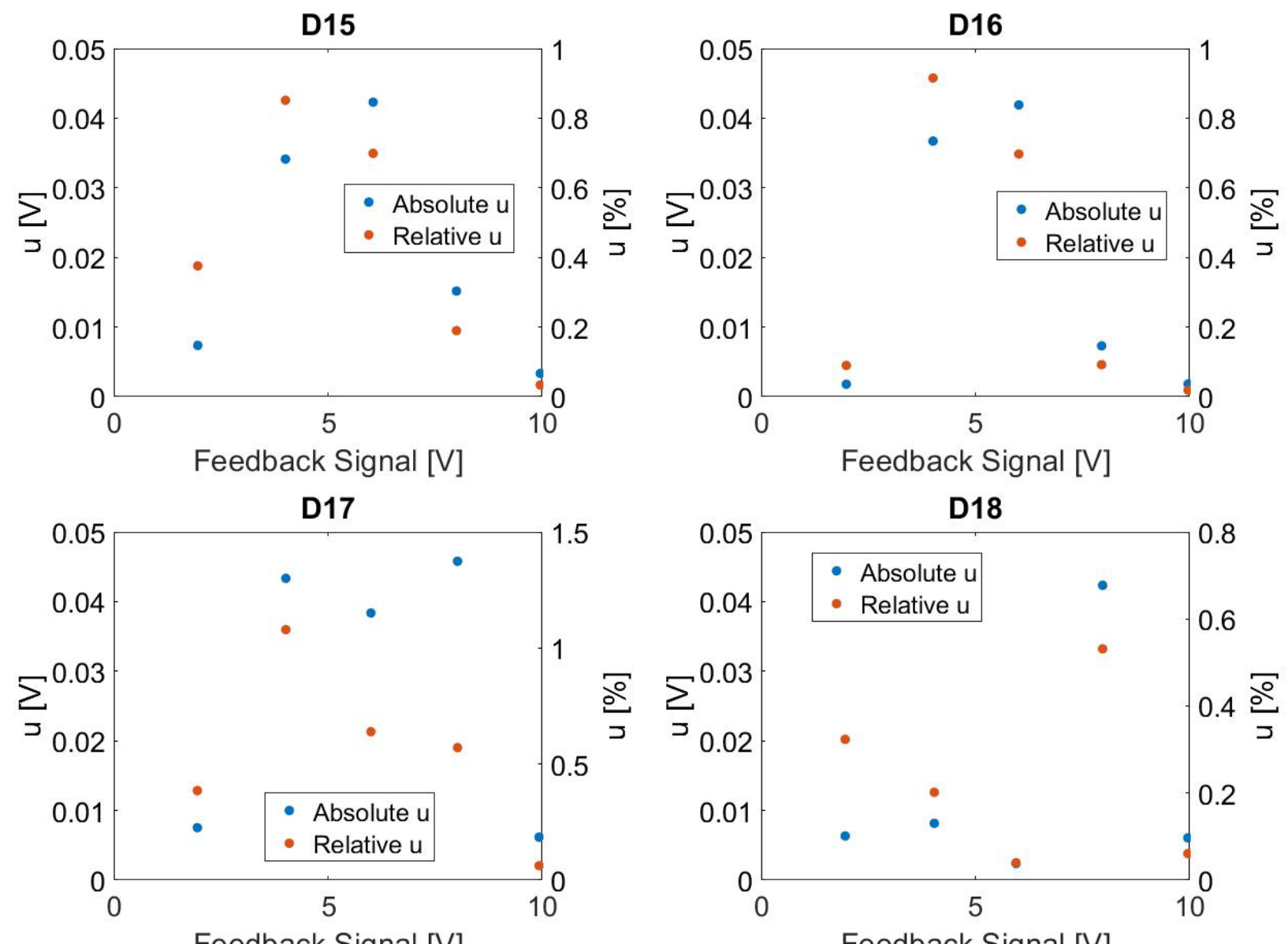

Feedback Signal [V]

Feedback Signal [V]

Figure 21. Total uncertainty for the damper actuators in the VAVs. 

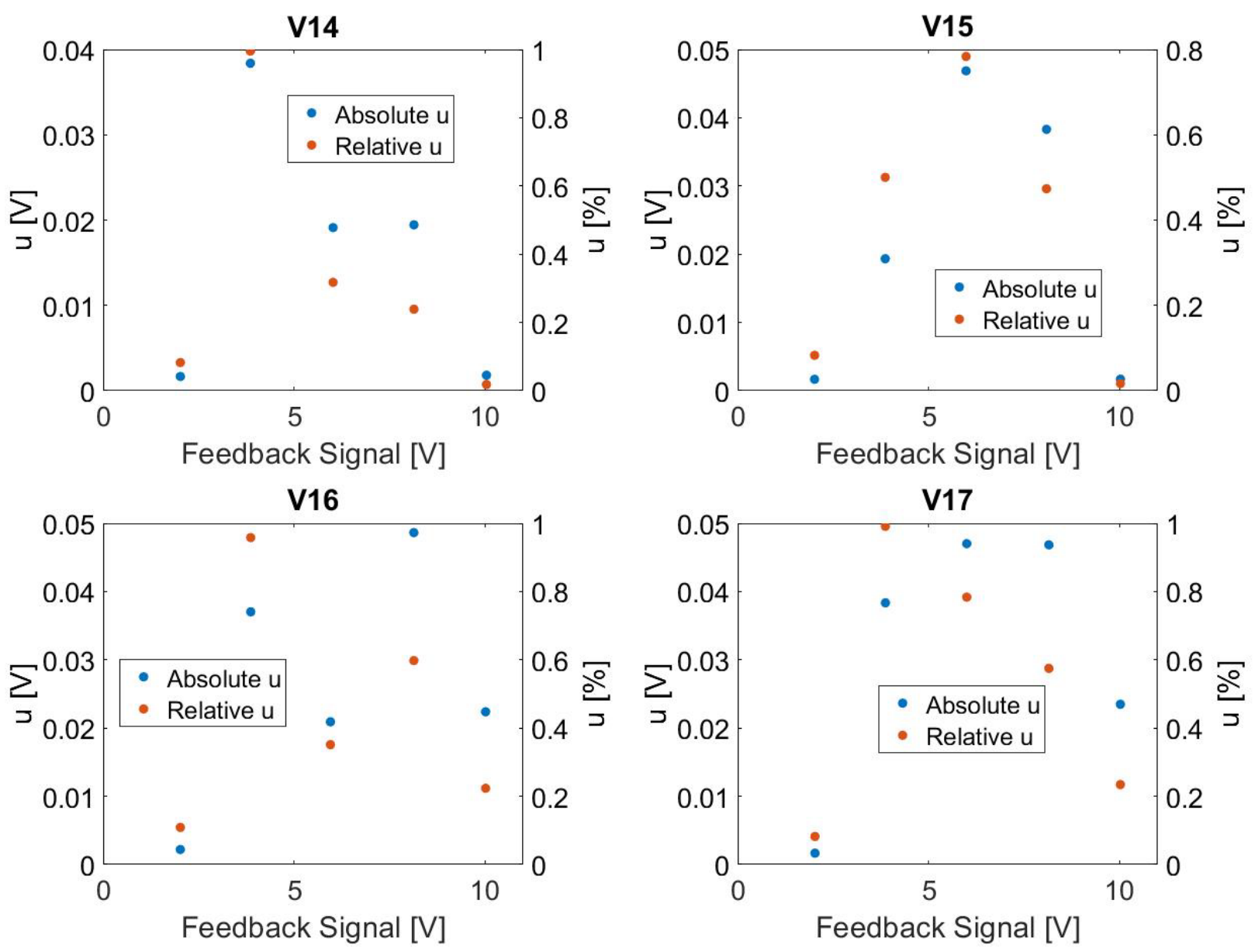

Figure 22. Total uncertainty for the valve actuators in the ZSs. 
Table 12. Uncertainties for the damper and valve actuators.

\begin{tabular}{|c|c|c|c|c|c|}
\hline \multirow[t]{2}{*}{ Device } & \multirow{2}{*}{$\begin{array}{l}\text { Channel } \\
\text { Number }\end{array}$} & \multirow{2}{*}{$\begin{array}{c}\text { Actuator Part } \\
\text { Number }\end{array}$} & \multicolumn{3}{|c|}{ Uncertainty [V] } \\
\hline & & & $\leq 1.5 \mathrm{~V}$ & $1.5 \mathrm{~V}<\mathrm{V} \leq 9 \mathrm{~V}$ & $>9 \mathrm{~V}$ \\
\hline $\mathrm{D} 2$ & 304 & GMA161.1P & & 0.063 & 0.27 \\
\hline D3 & 305 & GMA161.1P & & 0.078 & 0.34 \\
\hline D4 & 309 & GMA161.1P & \multicolumn{3}{|c|}{0.021} \\
\hline V2 & 359 & NVF24-MFT-E US & \multicolumn{3}{|c|}{0.019} \\
\hline D5 & 310 & GMA161.1P & \multicolumn{3}{|c|}{0.026} \\
\hline D6 & 329 & GMA161.1P & 0.38 & 0.037 & 0.17 \\
\hline D8 & 335 & GMA161.1P & 0.12 & \multicolumn{2}{|l|}{0.022} \\
\hline D7 & 328 & GMA161.1P & & 0.049 & 0.24 \\
\hline D15 & 336 & LMB24-SR-T & \multicolumn{3}{|c|}{0.042} \\
\hline D16 & 360 & LMB24-SR-T & \multicolumn{3}{|c|}{0.042} \\
\hline D17 & 363 & LMB24-SR-T & \multicolumn{3}{|c|}{0.042} \\
\hline D18 & 364 & LMB24-SR-T & \multicolumn{3}{|c|}{0.042} \\
\hline V14 & 385 & MS51-7103-100 & \multicolumn{3}{|c|}{0.038} \\
\hline V15 & 386 & MS51-7103-100 & \multicolumn{3}{|c|}{0.047} \\
\hline V16 & 387 & MS51-7103-100 & \multicolumn{3}{|c|}{0.049} \\
\hline V17 & 388 & MS51-7103-100 & \multicolumn{3}{|c|}{0.047} \\
\hline
\end{tabular}

\section{Summary}

This report presented the total measurement uncertainty of instruments in the air system associated with fans and the actuators for dampers and steam valves. Those calculations included the time-dependent variability of these devices. The results of this analysis will be used in reporting the uncertainty of measurements in the IBAL in future publications. Now that the uncertainties have been established, the strength of the conclusions drawn from experiments in the IBAL can be determined.

\section{References}

[1] A. J. Pertzborn, "NIST Technical Note 1933: Intelligent Building Agents Laboratory : Hydronic System Design,” 2016.

[2] A. J. Pertzborn and D. A. Veronica, "NIST Technical Note 2025: Intelligent Building Agents Laboratory: Air System Design," 2018.

[3] A. J. Pertzborn, "NIST Technical Note 1970: Measurement Uncertainty in the Hydronic System in the IBAL," 2017.

[4] NIST, "NIST/SEMATECH e-Handbook of Statistical Methods," 2013. [Online]. Available: https://www.itl.nist.gov/div898/handbook/. [Accessed: 06-Sep-2018]. 


\section{Appendix: Uncertainty Data}

Tables 13 through 33 contain the full uncertainty data from Figures 8 through 12 and 18 through 22. Tables 34 through 43 show the ratio of time-dependent variability to the instrument and manufacturer uncertainty:

$$
\sqrt{(\text { time }- \text { dependent })^{2} /\left[(\text { instrument })^{2}+(\text { manufacturer })^{2}\right]}
$$

Table 13 Uncertainty results for the instruments related to the OAU fan.

\begin{tabular}{|c|c|c|c|c|}
\hline \multirow{2}{*}{ Control Signal [Hz] } & \multicolumn{2}{|c|}{ Airflow } & \multicolumn{2}{c|}{ Power } \\
\cline { 2 - 5 } & $\mathbf{u}\left[\mathbf{m}^{\mathbf{3}} \mathbf{h}\right]$ & $\mathbf{u}[\%]$ & $\mathbf{u}[\mathbf{W}]$ & $\mathbf{u}[\%]$ \\
\hline 15 & 52.8 & 1.60 & 11.1 & 9.40 \\
\hline 30 & 62.3 & 1.58 & 12.9 & 2.64 \\
\hline 45 & 74.3 & 1.66 & 30.9 & 2.00 \\
\hline 60 & 83.0 & 1.62 & 58.0 & 1.61 \\
\hline
\end{tabular}

Table 14 Uncertainty results for the instruments related to the AHU1 fan.

\begin{tabular}{|c|c|c|c|c|c|c|c|c|}
\hline \multirow{2}{*}{$\begin{array}{c}\text { Control } \\
\text { Signal [Hz] }\end{array}$} & \multicolumn{2}{|c|}{ Supply Airflow } & \multicolumn{2}{c|}{ Return Airflow } & \multicolumn{2}{c|}{ Power } & \multicolumn{2}{c|}{ Downstream Pressure } \\
\cline { 2 - 9 } & $\mathbf{u}\left[\mathbf{m}^{\mathbf{3}} \mathbf{h}\right]$ & $\mathbf{u}[\%]$ & $\mathbf{u}\left[\mathbf{m}^{3} \mathbf{h}\right]$ & $\mathbf{u}[\%]$ & $\mathbf{u}[\mathbf{W}]$ & $\mathbf{u}[\%]$ & $\mathbf{u}[\mathbf{P a}]$ & $\mathbf{u}[\%]$ \\
\hline 15 & 30.6 & 2.68 & 16.5 & 3.11 & 9.6 & 11.01 & 2.5 & 80.2 \\
\hline 30 & 39.1 & 2.66 & 7.9 & 65.4 & 11.7 & 4.32 & 3.0 & 6.65 \\
\hline 45 & 46.6 & 2.53 & 16.9 & 2.90 & 17.1 & 2.40 & 2.9 & 2.62 \\
\hline 60 & 52.1 & 2.25 & 26.2 & 2.46 & 31.5 & 2.06 & 1.8 & 1.40 \\
\hline
\end{tabular}

Table 15 Uncertainty results for the instruments related to the AHU2 fan.

\begin{tabular}{|c|c|c|c|c|c|c|c|c|}
\hline \multirow{2}{*}{$\begin{array}{c}\text { Control } \\
\text { Signal [Hz] }\end{array}$} & \multicolumn{2}{|c|}{ Supply Airflow } & \multicolumn{2}{c|}{ Return Airflow } & \multicolumn{2}{c|}{ Power } & \multicolumn{2}{c|}{ Downstream Pressure } \\
\cline { 2 - 9 } & $\mathbf{u}\left[\mathbf{m}^{\mathbf{3}} \mathbf{h}\right]$ & $\mathbf{u}[\%]$ & $\mathbf{u}\left[\mathbf{m}^{\mathbf{3}} \mathbf{h}\right]$ & $\mathbf{u}[\%]$ & $\mathbf{u}[\mathbf{W}]$ & $\mathbf{u}[\%]$ & $\mathbf{u}[\mathbf{P a}]$ & $\mathbf{u}[\%]$ \\
\hline 15 & 32.1 & 2.53 & 20.7 & 3.34 & 16.1 & 17.22 & 1.3 & 988.2 \\
\hline 30 & 39.9 & 2.27 & 10.3 & 3.0 & 18.0 & 6.50 & 2.2 & 5.21 \\
\hline 45 & 49.0 & 2.22 & 9.7 & 3.75 & 22.5 & 3.15 & 2.3 & 2.08 \\
\hline 60 & 56.4 & 2.13 & 17.7 & 2.53 & 34.5 & 2.29 & 1.3 & 1.00 \\
\hline
\end{tabular}

Table 16 Uncertainty results for the instruments related to the EXF1 fan.

\begin{tabular}{|c|c|c|c|c|}
\hline \multirow{2}{*}{ Control Signal [Hz] } & \multicolumn{2}{|c|}{ Airflow } & \multicolumn{2}{c|}{ Power } \\
\cline { 2 - 5 } & $\mathbf{u}\left[\mathbf{m}^{\mathbf{3}} \mathbf{h} \mathbf{h}\right.$ & $\mathbf{u}[\%]$ & $\mathbf{u}[\mathbf{W}]$ & $\mathbf{u}[\%]$ \\
\hline 15 & 31.7 & 2.54 & 6.1 & 9.06 \\
\hline 30 & 38.0 & 2.32 & 9.0 & 6.02 \\
\hline 45 & 50.3 & 2.26 & 17.4 & 5.51 \\
\hline 60 & 58.6 & 2.09 & 30.8 & 5.09 \\
\hline
\end{tabular}


Table 17 Uncertainty results for the instruments related to the EXF2 fan.

\begin{tabular}{|c|c|c|c|c|}
\hline \multirow{2}{*}{ Control Signal [Hz] } & \multicolumn{2}{|c|}{ Airflow } & \multicolumn{2}{c|}{ Power } \\
\cline { 2 - 5 } & $\mathbf{u}\left[\mathbf{m}^{\mathbf{3}} \mathbf{h}\right]$ & $\mathbf{u}[\%]$ & $\mathbf{u}[\mathbf{W}]$ & $\mathbf{u}[\%]$ \\
\hline 15 & 27.9 & 2.26 & 7.0 & 10.47 \\
\hline 30 & 35.7 & 2.22 & 9.3 & 5.91 \\
\hline 45 & 48.1 & 2.13 & 17.8 & 5.34 \\
\hline 60 & 61.9 & 2.14 & 30.2 & 4.69 \\
\hline
\end{tabular}

Table 18 Uncertainty results for the D2 actuator.

\begin{tabular}{|c|c|c|c|}
\hline Control Signal [V] & Feedback Signal [V] & $\mathbf{u}[\mathbf{V ]}$ & $\mathbf{u}[\%]$ \\
\hline 0 & -0.16 & 0.026 & -16.3 \\
\hline 1.5 & 1.40 & 0.015 & 1.09 \\
\hline 3.5 & 3.44 & 0.032 & 0.93 \\
\hline 5.5 & 5.52 & 0.063 & 1.15 \\
\hline 7.5 & 7.57 & 0.034 & 0.45 \\
\hline 9.5 & 8.64 & 0.266 & 3.08 \\
\hline
\end{tabular}

Table 19 Uncertainty results for the D3 actuator.

\begin{tabular}{|c|c|c|c|}
\hline Control Signal [V] & Feedback Signal [V] & $\mathbf{u}[\mathbf{V ]}$ & $\mathbf{u}[\%]$ \\
\hline 0 & -0.15 & 0.031 & -19.8 \\
\hline 1.5 & 1.39 & 0.021 & 1.52 \\
\hline 3.5 & 3.46 & 0.034 & 0.97 \\
\hline 5.5 & 5.51 & 0.027 & 0.49 \\
\hline 7.5 & 7.50 & 0.078 & 1.04 \\
\hline 9.5 & 7.49 & 0.342 & 4.57 \\
\hline
\end{tabular}

Table 20 Uncertainty results for the D4 actuator.

\begin{tabular}{|c|c|c|c|}
\hline Control Signal [V] & Feedback Signal [V] & u [V] & u [\%] \\
\hline 0 & 0.11 & 0.004 & 3.97 \\
\hline 1.5 & 1.41 & 0.021 & 1.47 \\
\hline 3.5 & 3.45 & 0.014 & 0.41 \\
\hline 5.5 & 5.51 & 0.013 & 0.23 \\
\hline 7.5 & 7.54 & 0.010 & 0.13 \\
\hline 9.5 & 9.19 & 0.008 & 0.09 \\
\hline
\end{tabular}


Table 21 Uncertainty results for the D5 actuator.

\begin{tabular}{|c|c|c|c|}
\hline Control Signal [V] & Feedback Signal [V] & u [V] & u [\%] \\
\hline 0 & 0.11 & 0.006 & 5.06 \\
\hline 1.5 & 1.40 & 0.013 & 0.90 \\
\hline 3.5 & 3.46 & 0.019 & 0.55 \\
\hline 5.5 & 5.51 & 0.026 & 0.46 \\
\hline 7.5 & 7.57 & 0.012 & 0.16 \\
\hline 9.5 & 9.23 & 0.011 & 0.12 \\
\hline
\end{tabular}

Table 22 Uncertainty results for the D6 actuator.

\begin{tabular}{|c|c|c|c|}
\hline Control Signal [V] & Feedback Signal [V] & $\mathbf{u}[\mathbf{V}]$ & $\mathbf{u}[\%]$ \\
\hline 0 & 0.29 & 0.381 & 130.4 \\
\hline 1.5 & 1.42 & 0.037 & 2.61 \\
\hline 3.5 & 3.49 & 0.023 & 0.67 \\
\hline 5.5 & 5.54 & 0.023 & 0.41 \\
\hline 7.5 & 7.60 & 0.021 & 0.28 \\
\hline 9.5 & 8.74 & 0.174 & 1.99 \\
\hline
\end{tabular}

Table 23 Uncertainty results for the D7 actuator.

\begin{tabular}{|c|c|c|c|}
\hline Control Signal [V] & Feedback Signal [V] & $\mathbf{u}[\mathbf{V}]$ & $\mathbf{u}[\%]$ \\
\hline 0 & -0.11 & 0.032 & -28.8 \\
\hline 1.5 & 1.43 & 0.036 & 2.55 \\
\hline 3.5 & 3.49 & 0.031 & 0.89 \\
\hline 5.5 & 5.53 & 0.021 & 0.38 \\
\hline 7.5 & 7.52 & 0.049 & 0.65 \\
\hline 9.5 & 7.73 & 0.244 & 3.15 \\
\hline
\end{tabular}

Table 24 Uncertainty results for the D8 actuator.

\begin{tabular}{|c|c|c|c|}
\hline Control Signal [V] & Feedback Signal [V] & $\mathbf{u}[\mathbf{V}]$ & $\mathbf{u}[\%]$ \\
\hline 0 & 0.26 & 0.119 & 46.1 \\
\hline 1.5 & 1.39 & 0.022 & 1.57 \\
\hline 3.5 & 3.46 & 0.016 & 0.47 \\
\hline 5.5 & 5.50 & 0.011 & 0.19 \\
\hline 7.5 & 7.53 & 0.005 & 0.07 \\
\hline 9.5 & 9.58 & 0.007 & 0.07 \\
\hline
\end{tabular}


Table 25 Uncertainty results for the D15 actuator.

\begin{tabular}{|c|c|c|c|}
\hline Control Signal [V] & Feedback Signal [V] & $\mathbf{u}[\mathbf{V ]}$ & $\mathbf{u}[\%]$ \\
\hline 2 & 1.96 & 0.007 & 0.38 \\
\hline 4 & 4.01 & 0.034 & 0.85 \\
\hline 6 & 6.05 & 0.042 & 0.70 \\
\hline 8 & 8.00 & 0.015 & 0.19 \\
\hline 10 & 9.95 & 0.003 & 0.03 \\
\hline
\end{tabular}

Table 26 Uncertainty results for the D16 actuator.

\begin{tabular}{|c|c|c|c|}
\hline Control Signal [V] & Feedback Signal [V] & $\mathbf{u}[\mathbf{~ [ ] ~}$ & $\mathbf{u}[\%]$ \\
\hline 2 & 1.99 & 0.002 & 0.09 \\
\hline 4 & 4.01 & 0.037 & 0.92 \\
\hline 6 & 6.01 & 0.042 & 0.70 \\
\hline 8 & 7.94 & 0.007 & 0.09 \\
\hline 10 & 9.96 & 0.002 & 0.02 \\
\hline
\end{tabular}

Table 27 Uncertainty results for the D17 actuator.

\begin{tabular}{|c|c|c|c|}
\hline Control Signal [V] & Feedback Signal [V] & $\mathbf{u}[\mathbf{~}]$ & $\mathbf{u}[\%]$ \\
\hline 2 & 1.95 & 0.008 & 0.39 \\
\hline 4 & 4.02 & 0.043 & 1.08 \\
\hline 6 & 6.00 & 0.038 & 0.64 \\
\hline 8 & 8.02 & 0.046 & 0.57 \\
\hline 10 & 9.93 & 0.006 & 0.06 \\
\hline
\end{tabular}

Table 28 Uncertainty results for the D18 actuator.

\begin{tabular}{|c|c|c|c|}
\hline Control Signal [V] & Feedback Signal [V] & $\mathbf{u}[\mathbf{V ]}$ & $\mathbf{u}[\%]$ \\
\hline 2 & 1.96 & 0.006 & 0.32 \\
\hline 4 & 4.04 & 0.008 & 0.20 \\
\hline 6 & 5.95 & 0.002 & 0.04 \\
\hline 8 & 7.97 & 0.042 & 0.53 \\
\hline 10 & 9.96 & 0.006 & 0.06 \\
\hline
\end{tabular}


Table 29 Uncertainty results for the V2 actuator.

\begin{tabular}{|c|c|c|c|}
\hline Control Signal [V] & Feedback Signal [V] & $\mathbf{u}[\mathbf{V ]}$ & $\mathbf{u}[\%]$ \\
\hline 2 & 1.99 & 0.005 & 0.24 \\
\hline 4 & 3.94 & 0.008 & 0.19 \\
\hline 6 & 5.92 & 0.014 & 0.24 \\
\hline 8 & 7.91 & 0.016 & 0.21 \\
\hline 10 & 9.89 & 0.019 & 0.19 \\
\hline
\end{tabular}

Table 30 Uncertainty results for the V14 actuator.

\begin{tabular}{|c|c|c|c|}
\hline Control Signal [V] & Feedback Signal [V] & $\mathbf{u}[\mathbf{V}]$ & $\mathbf{u}[\%]$ \\
\hline 2 & 2.02 & 0.002 & 0.08 \\
\hline 4 & 3.86 & 0.038 & 1.00 \\
\hline 6 & 6.02 & 0.019 & 0.32 \\
\hline 8 & 8.14 & 0.019 & 0.24 \\
\hline 10 & 10.04 & 0.002 & 0.02 \\
\hline
\end{tabular}

Table 31 Uncertainty results for the V15 actuator.

\begin{tabular}{|c|c|c|c|}
\hline Control Signal [V] & Feedback Signal [V] & $\mathbf{u}[\mathbf{V}]$ & $\mathbf{u}[\%]$ \\
\hline 2 & 2.01 & 0.002 & 0.08 \\
\hline 4 & 3.86 & 0.019 & 0.50 \\
\hline 6 & 5.98 & 0.047 & 0.78 \\
\hline 8 & 8.09 & 0.038 & 0.47 \\
\hline 10 & 10.02 & 0.002 & 0.02 \\
\hline
\end{tabular}

Table 32 Uncertainty results for the V16 actuator.

\begin{tabular}{|c|c|c|c|}
\hline Control Signal [V] & Feedback Signal [V] & $\mathbf{u}[\mathbf{~ [ ] ~}$ & $\mathbf{u}[\%]$ \\
\hline 2 & 2.02 & 0.002 & 0.11 \\
\hline 4 & 3.86 & 0.037 & 0.96 \\
\hline 6 & 5.95 & 0.021 & 0.35 \\
\hline 8 & 8.14 & 0.049 & 0.60 \\
\hline 10 & 10.02 & 0.022 & 0.22 \\
\hline
\end{tabular}

Table 33 Uncertainty results for the V17 actuator.

\begin{tabular}{|c|c|c|c|}
\hline Control Signal [V] & Feedback Signal [V] & $\mathbf{u}[\mathbf{V ]}$ & $\mathbf{u}[\%]$ \\
\hline 2 & 2.02 & 0.002 & 0.08 \\
\hline 4 & 3.87 & 0.038 & 0.99 \\
\hline 6 & 6.00 & 0.047 & 0.78 \\
\hline 8 & 8.15 & 0.047 & 0.57 \\
\hline 10 & 10.02 & 0.023 & 0.23 \\
\hline
\end{tabular}


Table 34 Time-dependent variability versus instrument and manufacturer uncertainty for the instruments associated with the OAU fan.

\begin{tabular}{|c|c|c|}
\hline Control Signal [V] & Airflow & Power \\
\hline 15 & 0.46 & 14.51 \\
\hline 30 & 0.45 & 16.96 \\
\hline 45 & 0.59 & 40.62 \\
\hline 60 & 0.53 & 76.34 \\
\hline
\end{tabular}

Table 35 Time-dependent variability versus instrument and manufacturer uncertainty for the instruments associated with the AHU1 fan.

\begin{tabular}{|c|c|c|c|c|}
\hline $\begin{array}{c}\text { Control } \\
\text { Signal [V] }\end{array}$ & $\begin{array}{c}\text { Supply } \\
\text { Airflow }\end{array}$ & $\begin{array}{c}\text { Return } \\
\text { Airflow }\end{array}$ & Power & $\begin{array}{c}\text { Downstream } \\
\text { Pressure }\end{array}$ \\
\hline 15 & 0.81 & 1.08 & 3.74 & 2.14 \\
\hline 30 & 0.82 & 1.89 & 4.62 & 3.35 \\
\hline 45 & 0.74 & 0.95 & 6.86 & 4.30 \\
\hline 60 & 0.48 & 0.69 & 12.69 & 0.17 \\
\hline
\end{tabular}

Table 36 Time-dependent variability versus instrument and manufacturer uncertainty for the instruments associated with the AHU2 fan.

\begin{tabular}{|c|c|c|c|c|}
\hline $\begin{array}{c}\text { Control } \\
\text { Signal [V] }\end{array}$ & $\begin{array}{c}\text { Supply } \\
\text { Airflow }\end{array}$ & $\begin{array}{c}\text { Return } \\
\text { Airflow }\end{array}$ & Power & $\begin{array}{c}\text { Downstream } \\
\text { Pressure }\end{array}$ \\
\hline 15 & 0.70 & 1.25 & 6.42 & 1.78 \\
\hline 30 & 0.49 & 0.85 & 7.23 & 2.75 \\
\hline 45 & 0.45 & 1.15 & 9.07 & 3.96 \\
\hline 60 & 0.34 & 0.70 & 13.92 & 0.03 \\
\hline
\end{tabular}

Table 37 Time-dependent variability versus instrument and manufacturer uncertainty for the instruments associated with the EXF1 fan.

\begin{tabular}{|c|c|c|}
\hline Control Signal [V] & Airflow & Power \\
\hline 15 & 0.76 & 2.24 \\
\hline 30 & 0.58 & 3.51 \\
\hline 45 & 0.52 & 6.96 \\
\hline 60 & 0.30 & 12.43 \\
\hline
\end{tabular}

Table 38 Time-dependent variability versus instrument and manufacturer uncertainty for the instruments associated with the EXF2 fan.

\begin{tabular}{|c|c|c|}
\hline Control Signal [V] & Airflow & Power \\
\hline 15 & 0.50 & 2.63 \\
\hline 30 & 0.47 & 3.63 \\
\hline 45 & 0.35 & 7.14 \\
\hline 60 & 0.38 & 12.19 \\
\hline
\end{tabular}


Table 39 Time-dependent variability versus instrument uncertainty for the damper actuators in the OAU.

\begin{tabular}{|c|c|c|c|}
\hline Control Signal [V] & D2 & D3 & D4 \\
\hline 0 & 15.8 & 18.4 & 2.4 \\
\hline 1.5 & 9.2 & 12.8 & 12.5 \\
\hline 3.5 & 19.2 & 20.3 & 8.4 \\
\hline 5.5 & 38.1 & 16.2 & 7.5 \\
\hline 7.5 & 20.6 & 47.2 & 5.7 \\
\hline 9.5 & 160.2 & 206.0 & 5.0 \\
\hline
\end{tabular}

Table 40 Time-dependent variability versus instrument uncertainty for the damper actuators in AHU1.

\begin{tabular}{|c|c|c|}
\hline Control Signal [V] & D5 & D6 \\
\hline 0 & 3.3 & 229.2 \\
\hline 1.5 & 7.5 & 22.2 \\
\hline 3.5 & 11.3 & 14.1 \\
\hline 5.5 & 15.4 & 13.7 \\
\hline 7.5 & 7.1 & 12.8 \\
\hline 9.5 & 6.5 & 105.0 \\
\hline
\end{tabular}

Table 41 Time-dependent variability versus instrument uncertainty for the damper actuators in AHU2.

\begin{tabular}{|c|c|c|}
\hline Control Signal [V] & D8 & D7 \\
\hline 0 & 71.8 & 19.4 \\
\hline 1.5 & 13.1 & 21.9 \\
\hline 3.5 & 9.8 & 18.8 \\
\hline 5.5 & 6.3 & 12.7 \\
\hline 7.5 & 2.8 & 29.2 \\
\hline 9.5 & 4.1 & 146.8 \\
\hline
\end{tabular}

Table 42 Time-dependent variability versus instrument uncertainty for the damper actuators in the VAVs.

\begin{tabular}{|c|c|c|c|c|}
\hline Control Signal [V] & D15 & D16 & D17 & D18 \\
\hline 2 & 4.3 & 0.4 & 4.4 & 3.7 \\
\hline 4 & 20.5 & 22.1 & 26.1 & 4.8 \\
\hline 6 & 25.5 & 25.2 & 23.1 & 1.0 \\
\hline 8 & 9.1 & 4.3 & 27.6 & 25.5 \\
\hline 10 & 1.7 & 0.5 & 3.6 & 3.5 \\
\hline
\end{tabular}


Table 43 Time-dependent variability versus instrument uncertainty for the steam valve actuators.

\begin{tabular}{|c|c|c|c|c|c|}
\hline Control Signal [V] & V2 & V14 & V15 & V16 & V17 \\
\hline 2 & 2.8 & 0.1 & 0.1 & 0.9 & 0.1 \\
\hline 4 & 4.5 & 23.1 & 11.6 & 22.3 & 23.1 \\
\hline 6 & 8.7 & 11.5 & 28.2 & 12.6 & 28.3 \\
\hline 8 & 9.8 & 11.7 & 23.0 & 29.3 & 28.2 \\
\hline 10 & 11.1 & 0.4 & 0.2 & 13.4 & 14.1 \\
\hline
\end{tabular}

